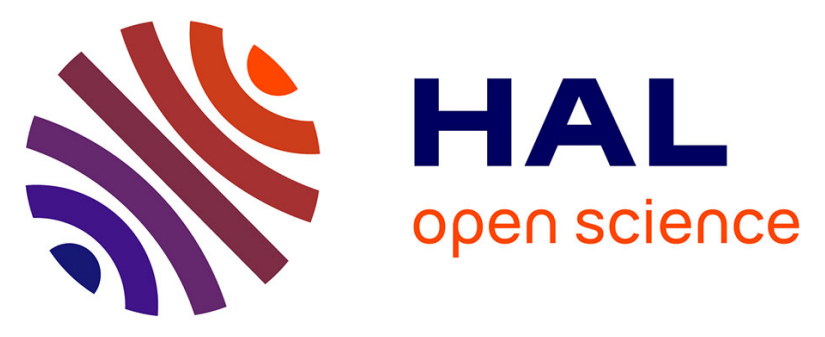

\title{
High-content analysis of larval phenotypes for the screening of xenobiotic toxicity using Phallusia mammillata embryos
}

\author{
Ievgeniia Gazo, Isa Gomes, Thierry Savy, Nadine Peyriéras, Lydia \\ Besnardeau, Celine Hebras, Sameh Benaicha, Manon Brunet, Olena \\ Shaliutina, Alex Mcdougall, et al.
}

\section{To cite this version:}

Ievgeniia Gazo, Isa Gomes, Thierry Savy, Nadine Peyriéras, Lydia Besnardeau, et al.. High-content analysis of larval phenotypes for the screening of xenobiotic toxicity using Phallusia mammillata embryos. Aquatic Toxicology, 2021, 232, pp.105768. 10.1016/j.aquatox.2021.105768 . hal-03146675

\section{HAL Id: hal-03146675 \\ https://hal.sorbonne-universite.fr/hal-03146675}

Submitted on 19 Feb 2021

HAL is a multi-disciplinary open access archive for the deposit and dissemination of scientific research documents, whether they are published or not. The documents may come from teaching and research institutions in France or abroad, or from public or private research centers.
L'archive ouverte pluridisciplinaire HAL, est destinée au dépôt et à la diffusion de documents scientifiques de niveau recherche, publiés ou non, émanant des établissements d'enseignement et de recherche français ou étrangers, des laboratoires publics ou privés. 


\section{High-content analysis of larval phenotypes for the screening of xenobiotic toxicity using}

4 Ievgeniia Gazo $^{1,2^{*}}$, Isa D. L. Gomes ${ }^{1}$, Thierry $\mathrm{Savy}^{3}$, Nadine Peyrieras $^{3}$, Lydia Besnardeau ${ }^{1}$,

5 Celine Hebras ${ }^{1}$, Sameh Benaicha ${ }^{1}$, Manon Brunet ${ }^{1}$, Olena Shaliutina ${ }^{2}$, Alex McDougall ${ }^{1}$ and

6 Rémi Dumollard ${ }^{1}$

$7 \quad{ }^{1}$ Sorbonne Universités, UPMC Univ Paris 06, CNRS, Laboratoire de Biologie du Développement de Villefranche-

8 sur-mer (LBDV), Observatoire Océanologique, 06230 Villefranche sur-mer, France

$9{ }^{2}$ University of South Bohemia in Ceske Budejovice, Faculty of Fisheries and Protection of Waters, South Bohemian

10 Research Center of Aquaculture and Biodiversity of Hydrocenoses, Research Institute of Fish Culture and 11 Hydrobiology, Zátiší 728/II, 389 25, Vodňany, Czech Republic

$12{ }^{3}$ BioEmergences Laboratory, CNRS USR 3695, 91190 Gif-sur-Yvette, France

* Corresponding author: I. Gazo; Zátiší 728/II, 389 25, Vodňany, Czech Republic; gazo@ frov.jcu.cz

\section{Abstract}

In recent years, pollution of surface waters with xenobiotic compounds became an issue of concern in society and has been the object of numerous studies. Most of these xenobiotic compounds are man-made molecules and some of them are qualified as endocrine disrupting chemicals (EDCs) when they interfere with hormones actions. Several studies have investigated the teratogenic impacts of EDCs in vertebrates (including marine vertebrates). However, the impact of such EDCs on marine invertebrates is much debated and still largely obscure. In addition, DNA-altering genotoxicants can induce embryonic malformations. The goal of this study is to develop a reliable and effective test for assessing toxicity of chemicals using embryos of the ascidian (Phallusia mammillata) in order to find phenotypic signatures associated with xenobiotics. We evaluated embryonic malformations with high-content analysis of larval phenotypes by scoring several quantitative and qualitative morphometric endpoints on a single image of Phallusia tadpole larvae

27 with semi-automated image analysis. Using this approach we screened different classes of toxicants including genotoxicants, known or suspected EDCs and nuclear receptors (NRs) ligands. 
29 The screen presented here reveals a specific phenotypic signature for ligands of retinoic acid 30 receptor/retinoid X receptor. Analysis of larval morphology combined with DNA staining revealed 31 that embryos with DNA aberrations displayed severe malformations affecting multiple aspects of 32 embryonic development. In contrast EDCs exposure induced no or little DNA aberrations and 33 affected mainly neural development. Therefore the ascidian embryo/larval assay presented here 34 can allow to distinguish the type of teratogenicity induced by different classes of toxicants.

35

36

37

38 Keywords: ascidian; embryo; toxicity; morphological analysis; endocrine disrupting chemical 39 (EDC); genotoxicity

40 


\section{INTRODUCTION}

42 Anthropogenic activities have a large impact on aquatic ecosystems from the discharge of chemical

43 substances, many of which are supposed to be present in trace amounts (i.e. heavy metals) or even

44 absent in natural conditions (i.e. pharmaceuticals, pesticides) (Mnif et al., 2011; Desbiolles et al.,

45 2018). Endocrine disrupting chemicals (EDCs) are xenobiotic substances that can interfere with

46 the endocrine system through two main pathways: the genomic pathway, via binding to nuclear

47 receptors (NRs); or the non-genomic pathway, via binding to cell membrane receptors or affecting

48 hormone metabolism. Thus endocrine disruption can be induced by xenobiotics that bind nuclear

49 receptors such as AR, ER, TR, PPAR, RXR, PXR, CAR or ERR (termed NR-binding EDCs) (Mnif

50 et al., 2011). Upon NR binding, EDCs can either activate a receptor (agonist action) or block it for

51 normal hormone (antagonistic action).

52 Many phenotypes of EDCs exposure have been described in invertebrate species (Urushitani et al.,

53 2018; Castro et al., 2007; le Maire et al., 2009; Nishikawa et al., 2004; Matsushima et al., 2013),

54 but the mode-of-action of these EDCs remains mainly unclear. One approach to predict whether a

55 xenobiotic might target a NR is to compare its phenotype against the phenotypes produced by a

56 specific NR agonist/antagonist (Tohmé et al., 2014, Gomes et al., 2019b). If a phenotypic signature

57 can be associated with a specific NR agonist/antagonist, then it can be potentially used as a

58 biomarker of NR-signaling disruption.

59 In the past years, ascidian species have been used as toxicological models (reviewed in Dumollard

60 et al., 2017; Zega et al., 2009; Gallo and Tosti, 2015; Battistoni et al., 2018). Ascidians are marine

61 filter-feeding chordates belonging to the Subphylum Urochordata, recognized as the sister group

62 of vertebrates (Delsuc et al., 2006). Their zygotes divide 13 to 15 times in 18 hours to give rise to 
63 a transparent vertebrate-like tadpole larvae (Yamada and Nishida, 2014). The ascidian larva 64 possesses both central and peripheral nervous system (CNS and PNS) (reviewed in Hudson, 2016;

65 Dumollard et al., 2017; Gomes et al., 2019a). The CNS of ascidian larvae is composed of a sensory 66 vesicle and a motor ganglion homologous, respectively, to the vertebrate diencephalon and 67 hindbrain (Holland and Holland, 1999). The sensory vesicle within the CNS contains two easily 68 identifiable dark pigmented sensory organs (PSO), the otolith (Ot) and the ocellus (Oc). The PNS 69 consists of the papillary neurons in palps, the epidermal sensory neurons, and the bipolar tail 70 neurons (Hudson, 2016). A prominent feature of ascidian larva are the adhesive organs, or palps, 71 which are part of the PNS (Takamura, 1998). Hence, a number of morphological features can be 72 assessed in the transparent ascidian larva to discriminate between non specific teratogenicity (i.e. 73 problems in general morphogenesis of the larva) and specific neurodevelopmental toxicity (i.e. 74 problems in the development of PNS and CNS structures). Ascidian neurodevelopment might be 75 especially sensitive to NR-targeting EDCs as several NRs are expressed in neurogenic domains of 76 the ascidian embryo (reviewed in Gomes et al., 2019a).

77 High-content analysis is a technique that involves scoring of multiple endpoints on a single image 78 which can be achieved by automated or semi-automated image analysis and is now commonly 79 applied to drug discovery screening using biological systems (Esner et al., 2018). The aim of this 80 study was to analyse the teratogenic effects of different classes of compounds (EDCs, NR ligands, 81 genotoxic and cytotoxic compounds) by quantifying larval malformations of the ascidian Phallusia 82 mammillata. We have hypothesized that by performing high-content analysis of morphological 83 malformations in Phallusia tadpole larvae, we will determine phenotypic signatures of different 84 types of compounds, such as a toxicant (sodium azide), genotoxicants (TBT, etoposide, mitomycin 85 C), known/susptected EDCs (lindane, atrazine, chlordane, chlorpyrifos, BPA, estradiol benzoate) 
and nuclear receptors (NRs) ligands. Etoposide, TBT, and mitomycin were used as reference

87 genotoxic compounds (Kirkland et al., 2016). The pesticides analyzed in the current study (lindane, atrazine, chlordane, chlorpyrifos), as well as BPA, are often referred to as EDCs (Mnif et al., 2011);

89 however, their mechanism of action in marine invertebrates is unknown. Our previous work showed that several NRs (RAR, PXR/VDR $\alpha$, PPAR, ROR, and ERR) are expressed in neurogenic

91 regions of Phallusia mammillata embryos (Gomes et al., 2019a, Gomes et al., 2019b). We analyzed known agonists/antagonists of these NRs, such as UVI3003 (RXR antagonist), all-trans retinoic acid (RAR agonist), rifampicin and SR12813 (PXR agonists), SR1078 (ROR agonist), BADGE (PPAR agonist), diethylstilbestrol, and 4-hydrotamoxifen (ERR antagonists).

To complement our morphometric analysis of embryonic development we also performed a genotoxicity assay. Genotoxicity is the loss of DNA structural or functional integrity. There are several protocols for analysing DNA damage induced by genotoxic compounds (OECD test N. 487; OECD test N. 473; OECD test N. 489) and some of them have been successfully applied to marine invertebrates (Dixon et al., 2002; Saotome et al., 1999;). However, it is not clear which phenotypic signature is associated with DNA damage and genotoxicity in the embryo. The ascidian embryo is an interesting model for scoring genotoxicity, since the spindle assembly checkpoint is not active at early stages of development (Chenevert et al., 2020). Thus, even upon DNA damage 103 the embryo will continue dividing without pausing to repair DNA damage, resulting in overt DNA aberrations such as micronuclei, multinucleated cells or DNA bridges.

We describe here methods for ascidian embryonic cultures and provide different morphological endpoints of the ascidan larva that can be scored to discriminate larval phenotypes. Such high content analysis of ascidian larval phenotypes can be coupled with DNA staining to correlate 
109 these protocols and found that genotoxicants affect all morphological endpoints whereas EDCs 110 and NR ligands affect mostly neural endpoints. 
112 2.1. Animals

113 Phallusia mammillata were collected at Sète (Etang de Tau, Mediterranean coast, France) and kept 114 in the aquaria of the "Centre de Ressources Biologiques" (CRB) of the Institut de la Mer à 115 Villefranche (IMEV) which is an EMBRC-France certified service (see https://www.embrc116 france.fr/fr/nos-services/fourniture-de-ressources-biologiques/organismes-modeles/ascidie-

117 phallusia-mammillata). Animals were maintained in the aquaria on open system with running 118 seawater ( $\mathrm{pH} 8.2 \pm 0.05$, salinity $40 \pm 0.5 \mathrm{ppt}$ ) at $16^{\circ} \mathrm{C}$ for at least two weeks before use. Animals 119 were fed 3 to 5 times per week with commercial microalgae concentrates (2-3 mL per aquarium 120 of 60 L), Shellfish diet 1800® and Isochrysis 1800® (Instant Algae®, Reed Mariculture Inc., 121 Campbell, CA, USA, 95008) purchased from a french distributor. Ascidian eggs were collected 122 by oviduct dissection. In order to ensure proper penetration of the studied compounds into eggs, 123 they were dechorionated with 0.1\% Trypsin (Sigma-Aldrich, T9201) in filtered sea water (FSW) 124 for $60 \mathrm{~min}$ at $20^{\circ} \mathrm{C}$, then transferred to fresh sea water and stored at $18^{\circ} \mathrm{C}$ until required. Sperm 125 was collected by syringe aspiration from a sperm duct and was activated with high $\mathrm{pH} 9.2$ sea 126 water for 10-20 min, then used to fertilize dechorionated eggs (Gomes et al., 2019b; see full 127 protocols on $\underline{\text { http://lbdv.obs-vlfr.fr/en/research/research_groups/ascidian-biocell- }}$ 128 group/projets/fertilization-and-meiosis/protocols.html). The embryos were reared in dark 129 conditions to avoid photodegradation of chemicals.

\subsection{Tested Chemicals}

131 Sodium azide (CAS Number: 26628-22-8; purity: $\geq 99 \%$ ), tributyltin (CAS Number 1461-22-9; $\geq$ 132 96\%), etoposide (CAS Number 33419-42-0; reference standard), atrazine (CAS Number 1912-24- 
133 9; analytical standard), lindane (CAS Number 58-89-9; analytical standard), chlordane (CAS 134 Number 5103-71-9; analytical standard), chlorpyrifos (CAS Number 2921-88-2; analytical 135 standard), SR12813 (CAS Number 126411-39-0; $\geq 98 \%$ ), diethylstilbestrol (CAS Number 56-53$1361 ; \geq 99 \%$ ), 4-hydroxytamoxifen (CAS Number 68392-35-8; analytical standard), rifampicin (CAS 137 Number 13292-46-1; $\geq 97 \%$ (HPLC)), mitomycin C (CAS Number 50-07-7; reference standard), 138 bisphenol A (CAS Number 80-05-7; $\geq 99 \%$ ), estradiol benzoate (CAS Number 50-50-0; $\geq 97 \%$ 139 (HPLC)), ATRA (CAS Number 302-79-4; $\geq 98 \%$ ), BMS493 (CAS Number 215030-90-3; $\geq 98 \%$ ), 140 and UVI3003 (CAS Number 847239-17-2; $\geq 98 \%$ ) were purchased from the Sigma-Aldrich Co. 141 (St Louis, MO, USA). BADGE (CAS Number 1675-54-3; $\geq 95 \%$ ) and SR1078 (CAS Number 142 1246525-60-9; $\geq 98 \%$ (HPLC)) were purchased from Tocris Bioscience (Bristol, UK). Table 1 143 shows tested compounds and concentrations used in the current study. We have performed toxicity 144 testing to determine the dose that will produce serious toxicological effects, therefore the 145 concentrations used in the current study were mostly higher than environmentally relevant.

\subsection{Experimental design}

147 All compounds were resuspended in DMSO for a stock concentration. Immediately before the 148 treatment, stock solutions were diluted with DMSO to a 10 000x working concentration. Finally, 149 prediluted stocks were added to the embryo culture medium (FSW, 5 mM TAPS, 0.5 mM EDTA, $150 \mathrm{pH} 8$, salinity $40 \pm 0.5 \mathrm{ppt}$ ) at 1:10 000 ratio giving the required concentration of a compound in 151 the medium and $0.01 \%$ DMSO $(\mathrm{v} / \mathrm{v})$. The same amount of DMSO $(0.01 \%$ in embryo culture 152 medium) was used as a vehicle control. All solutions were controlled to be at $\mathrm{pH} 8$ and prechilled 153 to $18^{\circ} \mathrm{C}$ prior to embryo exposure. Concentrations of compounds were selected based on 154 preliminary experiments. We have chosen the concentrations which induced malformations, but 
155 were not lethal (i.e. which did not induce $100 \%$ undevelopped embryos) or the highest soluble 156 concentration.

157 Dechorionated eggs (approximately 1000 eggs) were mixed with activated sperm (10\% $/ \mathrm{ml} \mathrm{diluted}$ 158 in FSW) in the embryo culture medium for fertilization (Sardet et al., 2011; Gomes et al., 2019b). 159 After fertilization, embryos were washed twice with FSW to remove excess of sperm and to avoid 160 polyspermy. Washed embryos at 1-cell stage were then transferred to 12 -well plates, each well is 161 coated with GF (gelatin/formaldehyde, see Sardet et al., 2011), at a concentration of 100 162 embryos/well. Each well contained either vehicle control or a tested concentration of compound 163 in a total of $3 \mathrm{~mL}$ of FSW. Plates with embryos were kept in dark humid chambers to avoid 164 photodegradation of xenobiotics at $18^{\circ} \mathrm{C}$. Embryos were left to develop to gastrula or neurula stage $165\left(7-9 \mathrm{hpf}\right.$ at $\left.18^{\circ} \mathrm{C}\right)$ and $\sim 30$ embryos were collected for genotoxicity analysis (Supplementary Fig.

166 1). The rest of embryos was left to develop to swimming larval stage (stage $26,22 \mathrm{hpf}$ at $18^{\circ} \mathrm{C}$; 167 see Gomes et al., 2019b). Embryos were exposed to tested compounds from 1-cell stage till 168 fixation.

169 When embryos in the control reached swimming larval stage, all cultures were fixed with $0.4 \%$ 170 formaldehyde to stop motility. Fixed embryos were transferred to a chamber slide and imaged with 171 a Zeiss Axiovert200 inverted microscope at 10X magnification. For each culture, a minimum of 17230 embryos were analyzed per treatment $(\mathrm{N}=30$ technical replicates $)$. Each experimental 173 condition was repeated at least 3 times ( $n=3$ biological replicates).

\section{2.4. Morphological analysis of phenotypes}

175 Analysis of the phenotypes at larval stage was performed with Toxicosis, a software developed in 176 our laboratory with a proprietary code and filed by the CNRS at the APP (Agency for the 
177 Protection of Programs) on July 13th 2018 under the reference 178 IDDN.FR.001.330013.000.S.P.2018.000.10000. The analyzed endpoints are summarized in 179 Supplementary Figure $2(\mathrm{~B}-\mathrm{H})$. We analyzed the total area of PSO (Oc+Ot area) and the distance 180 between Oc and Ot (Oc/Ot distance) in order to describe development of the central nervous 181 system. The presence/absence of palps was used as a marker of peripheral nervous system 182 development. The trunk length to width ratio (trunk L/W) and tail length reflect general 183 morphogenesis of the embryo.

184 The experiments were performed during years 2015 - 2019 in different seasons using wild animals 185 from Sète (Etang de Tau, Mediterranean coast, France). Thus variations in natural animal 186 population in addition to seasonal rearing conditions contributed to variations in morphological 187 parameters of control embryos (Table 2). In order to eliminate the effect of external factors we 188 have compared and normalized each endpoint with the corresponding value in the control group 189 (0.01\% DMSO) done on the same day. Statistical analysis was performed on the raw (not190 normalized) data using the Kruskal-Wallis test. Analyses were performed at a significance level 191 of 0.01 (for Oc/Ot area, Oc/Ot distance, trunk L/W ratio and tail length) or 0.05 (for \% embryos 192 with palps) using STATISTICA v. 13.0 software for Windows. Raw measurements and 193 normalized values are presented in Tables $2-5$.

194 In addition, normal, malformed or undevelopped embryos were scored manually. An embryo was 195 considered malformed if the embryo presented signs of antero-posterior elongation (indicating it 196 had undergone gastrulation) or if tadpoles had a crooked tail, an absence of tail, an absence of 197 PSO, or a brain protrusion were observed. Embryos were considered undeveloped if they failed to 198 reach neurula stage (no sign of anteroposterior elongation or gastrulation). We calculated the 199 percentage of: 1) normal embryos [number of normal embryos *100 / (number of normal + 
200

201

202

203

204

205

206

207

208

209

210

211

212

213

214

215

216

217

218

219

220

221 malformed + undeveloped)]; 2) malformed [number of malformed embryos *100 / (number of normal + malformed + undeveloped)]; 3) undeveloped [number of undeveloped embryos $* 100 /$ (number of normal + malformed + undeveloped)].

\subsection{Genotoxicity assay}

Embryos from gastrula to neurula stage were fixed with a fixation solution (4\% paraformaldehyde, 0.5 $\mathrm{M} \mathrm{NaCl}$ in PBS) for $1 \mathrm{~h}$ at $20^{\circ} \mathrm{C}$ on a shaker. Then the fixative was removed and embryos were washed twice with PBS. After washing, the samples were incubated in PBS containing $0.1 \%$ Triton $\mathrm{X}-100$ and $3 \%$ bovine serum albumin (PBSB) for $1 \mathrm{~h}$ at $20^{\circ} \mathrm{C}$ on a shaker. The embryos were stained with $1 \mu \mathrm{g} / \mathrm{ml}$ Hoechst in PBSB for $1-2 \mathrm{~h}$ at $20^{\circ} \mathrm{C}$ on a shaker. The embryos were either stained with Hoecsht only or double stained with Hoecsht and $4 \mathrm{ng} / \mathrm{ml}$ phalloidin in PBSB to observe both DNA and membrane. Double staining was done to ascertain the presence of DNA bridges between two cells and/or multiple nuclei within the same cell. Finally, the embryos were washed twice with PBSB and transferred on a glass slide. The DNA aberrations (multinucleated cells, micronuclei or DNA bridges) were imaged using a confocal Leica SP8 fitted with 40×/1.1NA water objective lens and scored manually. The number of embryos scored in each treatment is shown in Table 6. Embryos were exposed to etoposide $10 \mu \mathrm{M}$ as a positive control for DNA damage. The relationships between \% embryos with DNA aberrations, normal, malformed and undeveloped embryos were quantified according to the Spearman's correlation tests. The t-test was used to establish significance of the correlation between pairs of parameters at a significance level of 0.05 . 


\subsection{Morphometric analysis of larval development in untreated embryos}

224 Figure 1 and Table 2 show changes in the morphology of ascidian embryos, scored quantitatively 225 for PSO development (Oc/Ot area, Oc/Ot distance), trunk and tail morphogenesis (trunk L/W ratio, 226 tail length) and qualitatively for palps development (presence of palps). Such morphological 227 changes occur from stage 22 (late tailbud) to stage 26 (hatching larva, see 228 https://www.bpni.bio.keio.ac.jp/chordate/faba/1.4/top.html for staging) (Fig. 1 B-F). At 18 hour229 post-fertilization (hpf; stage 22), late tailbud embryos start to pigment their PSO (only one 230 pigmented area $=72 \pm 24 \mu \mathrm{m}^{2}$ ) and no palp is apparent at the anterior tip of the trunk (Fig. 1B). 231 At stage 23, two distinct pigment cells are visible, the otolith (Ot) and the ocellus (Oc) (forming 232 the PSO of an area of $253 \pm 64 \mu \mathrm{m}^{2}$; Oc/Ot distance $=18 \pm 8 \mu \mathrm{m}$ ) and palps are first visible (Fig.

233 1C). At stage 24, the pigment cells are separated from each other (the otolith positioned anteriorly 234 and the ocellus posteriorly; Oc/Ot distance $=23 \pm 6 \mu \mathrm{m}$ ), and the trunk starts to elongate (Trunk $235 \mathrm{~L} / \mathrm{W}=1.8 \pm 0.3 ;$ Fig. 1D). From this stage and up to stage 26, the ocellus and otolith continue to 236 spread and move apart from each other, while the trunk continues to elongate (Fig. 1E, 1F). The 237 tail length only increases until stage 23 and then remains constant (tail length is $\sim 500 \mu \mathrm{m}$, Table 238 2). The stage 26 was selected for further analysis of phenotypes induced by exposure to xenobiotics 239 as it is the developmental stage of hatching. At this stage PSO area (mentioned Oc+Ot area in 240 Table 2 and radar charts), PSO distance and tail length reach maximum, palps are fully developed. 241 Later stages are characterized by further trunk elongation, and tail shortening (data not shown, see 242 https://www.bpni.bio.keio.ac.jp/chordate/faba/1.4/top.html). Therefore in further analysis the 243 cultures were fixed and analysed when controls reached stage 26. 
246 When Phallusia embryos are exposed to toxic compounds, deviations from normal embryonic 247 development (i.e. malformations) can be observed as alterations in the quantified endpoints (PSO 248 area and distance, trunk L/W ratio, tail length), compared to untreated control larvae. Images of 249 larval phenotypes are presented in Supplementary Fig. 3. We first analysed the phenotypes induced 250 by exposure to a cytotoxic compound, sodium azide (SA), and to three genotoxicants, etoposide, 251 mitomycin and tributyltin (TBT) (Kirkland et al., 2016) (Table 3, Supplementary figure 3). All 252 four tested chemicals significantly affected all the assessed endpoints, resulting in an embryo 253 resembling a mid tailbud stage embryo (st 22-23, Fig. 1A-D; Supplementary Fig. 3).

254 Concerning the cytotoxicant, the maximum dose of SA tested (2.5 mM) decreased Oc/Ot distance 255 by $81 \%$, number of embryos with palps by $95 \%$, tail length by $42 \%$ and trunk L/W ratio by $43 \%$ 256 (Table 3). Exposure to $2.5 \mathrm{mM} \mathrm{SA}$ induced $86 \pm 14 \%$ of malformed, $12 \pm 12 \%$ normal, and $2 \pm 2$ 257 undevelopped embryos (Fig. 2). The lowest observed effective concentrations (LOEC) in our study 258 was $1 \mathrm{mM}$ for SA (Tables 1 and 3 ).

259 Mitomycin significantly reduced Oc/Ot distance, trunk L/W ratio, and tail length at $10 \mu \mathrm{M}$ (LOEC) 260 and the percentage of embryos with palps was also reduced at this dose (though P > 0.01) (Table 2613 ). At $60 \mu \mathrm{M}$, mitomycin strongly affected all endpoints and induced malformations in $91 \pm 5 \%$ of 262 embryos (Table 3; Supplementary Fig. 3). Exposure to etoposide at concentrations $50-75 \mathrm{nM}$ 263 affected PSO area (by $14 \%$ at $75 \mathrm{nM}$ ), Oc/Ot distance (by $42 \%$ at $75 \mathrm{nM}$ ), and trunk L/W ratio (by $26414 \%$ at $75 \mathrm{nM}$ ), but had no effect on tail length or on the percentage of embryos with palps (Table 265 3). At a higher dose of $100 \mathrm{nM}$, etoposide had an effect similar to SA and mitomycin $(60 \mu \mathrm{M})$, 266 affecting all studied endpoints (malformation rate 79 $\pm 16 \%$, Fig. 2). Similarly, TBT at $10-20 \mathrm{nM}$ 
267 induced a significant reduction of PSO area (by $40 \%$ at $10 \mathrm{nM} \mathrm{TBT}$ ), of Oc/Ot distance (by $52 \%$

268 at $10 \mathrm{nM}$ TBT), and trunk L/W ratio (by $27 \%$ at $10 \mathrm{nM} \mathrm{TBT)} \mathrm{(Table} \mathrm{3).} \mathrm{Exposure} \mathrm{to} \mathrm{a} \mathrm{high} \mathrm{dose}$

269 of TBT $(50 \mathrm{nM})$ also led to severe malformations in general morphology of the larvae, with $82 \pm 6 \%$

270 of malformed embryos (Fig. 2; Supplementary Fig. 3).

\subsection{Phenotypes induced by known/suspected EDCs}

272 Lindane exposure resulted in significant malformations in developing ascidian embryos at $10 \mu \mathrm{M}$.

273 This pesticide affected primarily the Oc/Ot distance (62\% of control value) and trunk L/W ratio

274 (76\% of control value) of ascidian larvae (Table 4, Supplementary Fig. 4). When the concentration

275 of compound was increased to $20 \mu \mathrm{M}$, the PSO area decreased to $20 \%$ of control value and distance

276 between PSO was $36 \%$ of that in control. At $20 \mu \mathrm{M}$ lindane $53.3 \pm 9 \%$ of embryos were malformed 277 (Fig. 3).

278 Similar malformations were observed in atrazine-exposed embryos (Table 4, Supplementary Fig.

279 4). Our results show that exposure to $25-70 \mu \mathrm{M}$ atrazine induce a small but significant decrease 280 in Oc/Ot distance (to $69 \%$ of the control value at $70 \mu \mathrm{M}$ ) and trunk $\mathrm{L} / \mathrm{W}$ ratio (87\% of the control 281 value at $70 \mu \mathrm{M}$ ) without affecting other parameters. Only $12 \pm 7 \%$ embryos were malformed and $28283 \pm 7 \%$ were normal at $70 \mu \mathrm{M}$ of atrazine (Fig. 3).

283 Bisphenol A (BPA), a xenoestrogen, had a very specific effect on ascidian embryos. All tested 284 concentrations of BPA $(5-10 \mu \mathrm{M})$ specifically and significantly reduced PSO pigmentation (PSO 285 area) and Oc/Ot distance (Table 4, Supplementary Fig. 4). The rate of malformed embryos reached $28653 \pm 8 \%$ after exposure to $10 \mu \mathrm{M}$ BPA with $39 \pm 6 \%$ normal embryos (Fig. 3).

287 Chlordane provoked phenotypes similar to lindane, with PSO area (86\% of control) and Oc/Ot 288 distance (73\% of control) affected at concentrations of $10 \mu \mathrm{M}$ (Table 4, Supplementary Fig. 4). 
289

290

291

292

293

294

295

296

297

298

299

300

301

302

The highest tested concentration $(50 \mu \mathrm{M})$ also decreased the trunk $\mathrm{L} / \mathrm{W}$ ratio (92\% of control), but tail length and palps formation were not significantly affected. Exposure to $50 \mu \mathrm{M}$ chlordane resulted in $38 \pm 6 \%$ malformed embryos and $59 \pm 7 \%$ normal embryos (Fig. 3).

A slightly different phenotype was observed after exposure of Phallusia embryos to chlorpyrifos (Table 4, Supplementary Fig. 4). Low concentrations $10-25 \mu \mathrm{M}$ affected only Oc+Ot area (85\% of the control value) and trunk $\mathrm{L} / \mathrm{W}$ ratio ( $89 \%$ of the control value). The highest tested concentration $(50 \mu \mathrm{M})$ induced significant reduction of PSO area (69\% of control), Oc/Ot distance ( $52 \%$ of control), trunk $\mathrm{L} / \mathrm{W}$ ratio ( $75 \%$ of the control value) and tail length (67\% of control), thus affecting also the morphogenesis of the tadpole and not only neural development. Chlorpyrifos at $50 \mu \mathrm{M}$ also induced malformations in $13 \pm 7 \%$ of exposed embryos (Fig. 3 ).

We have also analyzed the effect of $\beta$-Estradiol 3-benzoate (E2B), an ER ligand used in veterinary medicine, on Phallusia embryo development. Exposure to E2B did not affect any studied endpoint (Table 4, Fig. 3, Supplementary Fig. 4).

\subsection{Phenotypes induced by NR-agonists/antagonists}

We then analysed the phenotypes induced by compounds known to specifically bind a vertebrate NR. The RAR agonist all-trans retinoic acid (ATRA) and the RAR antagonist BMS493 both had a strong inhibitory effect on palp development (Table 5, Supplementary Fig. 5). Exposure to 0.1 $\mu \mathrm{M}$ ATRA significantly decreased the number of embryos with palps (36\% of the control value) without affecting other endpoints. Higher concentrations of ATRA also led to decreased trunk L/W ratio ( $85 \%$ of the control value at $1 \mu \mathrm{M}$ ). A similar phenotype was observed with the RAR inverse 
310

311

312

313

314

315

316

317

318

319

320

321

322

323

324

325

326

327

328

329

330

agonist, BMS493, which primarily affected palp development at $3 \mu \mathrm{M}$ (15\% of the control value) and slightly reduced PSO area (87\% of the control value) and the tail length (93\% of the control).

An RXR antagonist, UVI3003, at $1 \mu \mathrm{M}$ also significantly affected palps formation (40\% of the control value), and reduced PSO area (86\% of the control value) (Table 5, Supplementary Fig. 5). Exposure to $2 \mu \mathrm{M}$ of UVI3003 also led to tail shortening (63\% of the control value) and trunk rounding ( $92 \%$ of the control value).

In our study, 4-OHT affected embryo development at concentrations of 5-10 $\mu \mathrm{M}$ (Table 5, Supplementary Fig. 5). At $5 \mu \mathrm{M}$ 4-OHT reduced mainly the Oc/Ot distance (51\% of control) and the trunk $\mathrm{L} / \mathrm{W}$ ratio to a lesser extent ( $83 \%$ of the control). At $10 \mu \mathrm{M}$ tail length was slightly but significantly affected (to $88 \%$ of the corresponding control value). In contrast, DES affected Phallusia larval development already at $1 \mu \mathrm{M}$ by reducing PSO area (to 84\%), Oc/Ot distance (to $64 \%$ ) and trunk L/W ratio (to $80 \%$ of the corresponding control value; Table 5, Supplementary Fig. 5). At $2 \mu \mathrm{M}$ all studied endpoints were significantly affected, showing high toxicity of DES to developing ascidian embryos.

Rifampicin exposure significantly affected only Oc/Ot distance $(23 \%$ of control at $100 \mu \mathrm{M})$ and trunk L/W ratio (70\% of control at $100 \mu \mathrm{M}$; Table 5, Supplementary Fig. 5). Another PXR agonist SR12813 (which was not tested against ascidan PXR) also decreased the distance between PSOs (55\% of control at $3 \mu \mathrm{M})$ but affected other endpoints such as PSO area (80\% of control at $3 \mu \mathrm{M})$, and trunk elongation ( $84 \%$ of control at $3 \mu \mathrm{M}$ ) (Table 5, Supplementary Fig. 5). The highest tested concentration $(7.5 \mu \mathrm{M})$ significantly reduced all studied parameters, thus showing non-specific toxicity. 
331 Embryo exposure to the ROR $\alpha / \gamma$ agonist, SR1078, reduced PSO area (80\% of the control value) 332 and trunk L/W ratio (93\% of the control value) at $2 \mu \mathrm{M}$ (Table 5, Supplementary Fig. 5). At $5 \mu \mathrm{M}$ 333 of SR1078, all studied endpoints except the rate of embryos with palps were significantly reduced, 334 showing nonspecific toxicity of the compound.

335 Exposure of Phallusia embryos to BADGE, a PPAR antagonist, induced a phenotype similar to 336 lindane and atrazine (Table 5, Supplementary Fig. 5). At $1 \mu \mathrm{M}$ BADGE only the trunk L/W ratio 337 was significantly affected (87\% of control value). Higher concentrations of BADGE $(2-5 \mu \mathrm{M})$ 338 further reduced the trunk $\mathrm{L} / \mathrm{W}$ ratio (to $74 \%$ at $5 \mu \mathrm{M}$ ) and affected distance between PSO (to $57 \%$ 339 at $5 \mu \mathrm{M})$ without affecting the other endpoints.

\subsection{Measurement of the genotoxicity induced in ascidian embryos}

342 High concentrations of SA and reference genotoxicants (mitomycin, etoposide, TBT) affect all 343 endpoints in the tadpole larvae (Table 3, Fig. 2), resulting in arrest of development before stage 344 26. We assessed genotoxicity of these drugs by staining embryo DNA and scoring DNA 345 aberrations. Table 6 and Supplementary Fig. 6 show the scores of DNA aberrations induced by the 346 toxics, after imaging Hoechst-stained Phallusia embryos at gastrula and neurula stages.

347 In the control cultures, embryos showed well aligned nuclei of constant size and tightly packed 348 nuclear DNA in all 50 embryos (Supplementary Fig. 6A). Control cultures also showed more than $34980 \%$ of normally developed larvae at 22 hpf (stage 26), without major malformations (Fig. 2). 350 Following exposure to $2.5 \mathrm{mM}$ SA we observed appearance of few micronuclei and DNA 351 aberrations in $70 \%$ embryos, thus showing that such a dose of SA is genotoxic to ascidian embryos 352 (Table 6; Supplementary Fig. 6B). 
353 Similarly to SA-exposed embryos, micronuclei and multinucleated cells were observed in TBTexposed embryos at $50 \mathrm{nM}$ (Table 6, Supplementary Fig. 6C). In contrast, the embryos exposed to the reference genotoxic compound etoposide $(100 \mathrm{nM})$ exhibited severe DNA damage with 356 formation of DNA bridges in some cells (Table 6, Supplementary Fig. 6D). Exposed embryos were 357 able to develop to tadpole, but showed high rate of malformations (Fig. 2). The higher dose of 358 etoposide $(10 \mu \mathrm{M})$ also led to formation of DNA bridges, but in the whole embryo (Table 6, 359 Supplementary Fig. 6E). Such embryos developed normally till gastrula stage and did not show 360 any disorganization of cell pattern, the embryo development was blocked shortly after gastrulation 361 (100\% undeveloped embryos at 22hpf; Fig. 2). Another reference genotoxic compound, 362 mitomycin $\mathrm{C}(60 \mu \mathrm{M})$, induced formation of DNA bridges in every embryos (Table 6, 363 Supplementary Fig. 6F), but only in parts of the ectoderm (data not shown). Such embryos were 364 still able to develop to the tadpole with $91 \pm 5 \%$ of malformed and only $8 \pm 7 \%$ of undeveloped 365 embryos (Fig. 2).

366 We have also assessed whether high concentrations of EDCs (lindane, atrazine, BPA, chlordane, 367 and chlorpyrifos) were genotoxic to ascidian embryos. Most of the pesticides induced little or no 368 DNA damage in Phallusia embryos (Table 6). Exposure to $20 \mu \mathrm{M}$ lindane led to appearance of 369 few micronuclei per gastrula without affecting the pattern of cellular divisions (Supplementary 370 Fig. 6G). This low level of DNA damage is associated with $53.3 \pm 9 \%$ of malformed embryos (Fig. $3713)$. In presence of $70 \mu \mathrm{M}$ atrazine no DNA aberrations was observed and only $12 \pm 7 \%$ embryos 372 were malformed (Table 6; Fig. 3). Exposure to $50 \mu \mathrm{M}$ chlordane resulted in appearance of rare

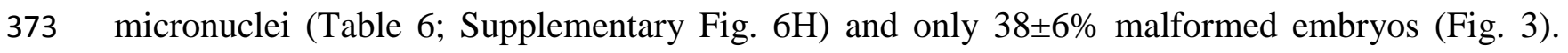
374 Chlorpyrifos at $50 \mu \mathrm{M}$ also had low genotoxic effect (Table 6) and induced malformations in 
$37513 \pm 7 \%$ of exposed embryos (Fig. 3). In the culture treated with $10 \mu \mathrm{M}$ BPA only 14 out of 119

376 embryos (11\%) were scored as having DNA aberrations (Table 6).

377 We have also analyzed correlation between the percentage of embryos showing DNA aberrations, 378 with the percentage of normal, malformed and undeveloped embryos (Table 7). According to 379 Spearman's test, the presence of DNA aberrations in Phallusia embryos exhibited a strong 380 negative correlation with the percentage of normal embryos in the culture $(r=-0.93, \mathrm{p}<0.05)$ and 381 showed not significant positive correlations with malformed $(r=0.5, \mathrm{p}>0.05)$ and undeveloped 382 embryos $(r=0.35, \mathrm{p}>0.05)$. 


\section{DISCUSSION}

385
We present here a test for developmental toxicity based on larval phenotypes of Phallusia mammillata embryos. Previous toxicological studies using ascidian embryos lacked standardized endpoints and protocols for quantification of larval malformations (Dumollard et al., 2017). The teratogenic potential of the tested xenobiotics was assessed by high content analysis of neurodevelopmental endpoints such as pigment sensory organs (PSO) area, distance between ocellus and otolith, rate of embryos with palps, as well as general morphogenesis endpoints such as trunk length/width ratio and tail length. We implemented serial embryonic cultures, imaged and analysed them by scoring quantitative and qualitative endpoints. Transparency of Phallusia larvae allows assessment of neurodevelopmental disorders without additional staining. This feature distinguish our model from existing tests on marine invertebrate embryos (Sarkar et al., 2006). Our assay also affords to determine the genotoxic potential of tested compounds in the same cohort of embryos, to correlate genotoxicity with teratogenicity.

Results obtained in the current study show that exposure to toxicants may either induce a phenotype restricted to one or two endpoints or result in malformations resembling a delay in embryonic development (when all endpoints are affected, Supplementary Fig. 3-5). Such delay in embryonic development in response to stress or DNA damage is well described in the literature (Häder et al., 2011; Chiarelli et al., 2019). Therefore phenotypes that show 4 or 5 affected endpoints were considered either non-specific or indicative of DNA damage. The distance between Oc and Ot is the most sensitive endpoint as it was affected by most treatments. The reduction of Oc/Ot distance can be used to determine LOEC values of the compounds. In contrast, specific phenotypes, such as the embryos without palps but with unaffected PSO or tail length, could be characteristic of some toxicants. For example, the rate of embryos with palps is mostly affected 
upon exposure to RAR/RXR ligands and the absence of palps may thus be a good indicator of alterations in the RAR/RXR pathway. Conversely, tail length was the least affected parameter demonstrating that tail extension is prevented only at high level of toxicity or in cases of 410 genotoxicity.

\subsection{Phenotypes of general toxicants and genotoxicants}

413 Etoposide, mitomycin, and TBT have been shown to induce DNA damage in numerous test 414 systems (reviewed in Kirkland et al., 2016). Our present protocol couples the scoring of DNA 415 aberrations with the morphometric analysis of larval phenotypes, in order to estimate the impact 416 of genotoxicity on teratogenicity. DNA problems can quickly accumulate in ascidian embryos as 417 the early embryo proliferates without an active spindle assembly checkpoint (Chenevert et al., 418 2020). Therefore, at gastrula and neurula stages DNA aberrations can be easily observed with 419 nuclei staining (in our study with Hoechst). Previous studies on sea urchin (Saotome et al., 1999) 420 and zebrafish (Le Bihanic et al., 2016) showed that mitomycin induced micronuclei formation at 421 concentrations $5 \mu \mathrm{g} / \mathrm{mL}$ and $0.03 \mu \mathrm{g} / \mathrm{mL}$ respectively. In our study, we observed genotoxicity of 422 mitomycin only at $60 \mu \mathrm{M}(20 \mu \mathrm{g} / \mathrm{mL})$. The longer exposure time in both sea urchin and zebrafish 423 protocols may explain their higher sensitivity. Nevertheless, our approach allowed us to see several 424 types of DNA damage (micronuclei, multinucleated cells, DNA bridges) and correlate them with 425 embryonic phenotypes in a shorter time.

426 DNA damage was associated with a significant reduction of all studied endpoints. Reduction of 427 all endpoints by SA, TBT, etoposide and mitomycin resulted in phenotypes resembling untreated 428 control embryos at stages 22-23. Interestingly, TBT and SA which are known to have cytotoxic 
429 effects (Oyanagi et al., 2015; Weyermann et al., 2005) induced formation of multinucleated cells

430 and micronuclei, whereas clastogenic genotoxicants (mitomycin $\mathrm{C}$ and etoposide) led to formation

431 of DNA bridges. Formation of DNA bridges in the whole embryo at gastrula stage led to complete

432 arrest in development (see etoposide $10 \mu \mathrm{M}$, Fig. 2).

433 TBT has been shown to affect embryo development in invertebrates (Alzieu, 2000; Gallo, Tosti, 434 2013; Matthiessen, 2019) and to slow down development rate in vertebrates (Bentivegna and 435 Piatkowski, 1998). Bellas et al (2005) found that TBT affects embryo development of the ascidian 436 Ciona intestinalis with $\mathrm{EC}_{50}$ at $7.1 \mu \mathrm{g} / \mathrm{l}(22 \mathrm{nM})$; our study revealed significant changes in PSO 437 parameters at a similar range of concentrations $(10-50 \mathrm{nM}$ TBT $)$. Even though no DNA 438 aberrations were observed at $10 \mathrm{nM}$ TBT (data not shown), the teratogenicity of such a dose of 439 TBT was detected as a reduction in PSO area and trunk L/W ratio. Higher concentrations of TBT $440(50 \mathrm{nM})$ induced micronuclei and multinucleated cells, demonstrating DNA damage associated 441 with reduction of the ratio of normal embryos in the culture.

442 Previous study have shown that $5 \mathrm{mM}$ SA inhibited myoplasmic reorganization and establishment 443 of anteroposterior axis in embryos of Ciona intestinalis (Ishii et al., 2014). In our study, embryos 444 of Phallusia were significantly affected by $1-2.5 \mathrm{mM}$ SA and DNA damage was observed after 445 exposure to $2.5 \mathrm{mM}$ SA. The phenotypes observed in Ciona embryos exposed to $5 \mathrm{mM}$ SA must 446 then be due to the strong genotoxic effect of SA at this dose.

447 Altogether, our observations show that mild DNA damage is reflected in micronuclei at the 448 gastrula/neurula stage and such DNA damage is permissive for development up to stage 23 (TBT, 449 SA). Ascidian embryos can also tolerate appearance of DNA bridges in the epidermis (mitomycin) 450 or in parts of the embryo (etoposide $100 \mathrm{nM}$ ). However, extensive DNA damage caused by 
451 accumulation of double strand breaks and formation of DNA bridges throughout the embryo 452 prevents development past stage 10 (gastrula). There was a strong negative correlation between 453 DNA damage and the percentage of normal embryos in the culture. Our study thus allows to 454 speculate that a high percentage of undeveloped embryos is indicative of strong genotoxicity of a 455 tested compound. In contrast observing embryos arrested at stage 22 (and before PSO 456 pigmentation) would indicate medium genotoxicity of the tested compounds. Nevertheless, further 457 studies are needed to confirm this finding.

458 The highest tested concentrations of xenobiotics $(20 \mu \mathrm{M}$ lindane, $50 \mu \mathrm{M}$ chlordane, and $50 \mu \mathrm{M}$ 459 chlorpyrifos, $10 \mu \mathrm{M}$ BPA) induced formation of micronuclei and the percentage of embryos with 460 DNA problems correlated positively with the percentage of embryos with malformations (Tables 461 6-7, Fig. 3). However, these concentrations of pesticides induced reduction of at least three studied 462 morphological parameters, but did not lead to the same phenotypes like genotoxicants. Our 463 previous studies showed severe genotoxicity of BPA at $40 \mu \mathrm{M}$ (Gomes et al., 2019b); however, a 464 small number of embryos with micronuclei was detected already at $10 \mu \mathrm{M}$ (Table 6). In contrast, 465 atrazine did not induce any detectable DNA damage, and only two endpoints were affected.

466 Taken together these results suggest that high concentrations of EDCs may induce DNA damage, 467 which severely affects embryo development. However, most of these xenobiotics (lindane, 468 atrazine, chlordane, chlorpyrifos, and BPA) induced embryonic phenotypes at lower 469 concentrations than the ones inducing mild DNA damage, indicating that their main mechanism 470 of action is not related to genotoxicity. 
473 We compared the phenotypic signature of EDCs with that of known NR ligands because a major 474 mode of action (MoA) of EDCs is via modification of NR activity. The presence of palps was 475 sensitive to RXR and RAR inhibition and activation, but because other NR ligands had overlapping 476 phenotypes it was not possible to find other specific phenotypic signatures.

477 Previous studies have shown that the retinoic acid (RA) signaling pathway regulates axial 478 patterning and neurogenesis in the developing central and peripheral nervous systems of chordates 479 including ascidians (Fujiwara and Kawamura, 2003; Nagatomo et al., 2003; Zieger et al., 2018). 480 RA signal is mediated by an RA-binding heterodimeric transcription factor consisting of RAR and 481 RXR (Mangelsdorf and Evans, 1995). Both receptors are expressed in neurogenic domains of 482 ascidian embryos (Nagatomo et al., 2003, Gomes et al., 2019a), thus their ligands can most likely 483 affect ascidian larval brain formation (Nagatomo et al., 2003). In the current study we analyzed 484 the effect of the RAR agonist all-trans retinoic acid (ATRA), of the RAR antagonist BMS493 and 485 of the RXR antagonist UVI3003, on Phallusia embryos. All compounds completely blocked 486 formation of the adhesive palps and slightly but consistently increased the distance between PSO. 487 These results are in agreement with previous studies (Dumollard et al., 2017; Nagatomo et al., 488 2003) showing similar phenotypes in ascidian embryos treated with ATRA. The similar 489 phenotypes induced by activation and inactivation of RAR can be explained by a downregulation 490 of RA metabolism in ATRA-exposed tailbud embryo (Nagatomo et al., 2003) as found in the 491 mouse (Lee at al., 2012) but this hypothesis should be confirmed in ascidians.

492 The RAR-orphan receptor (ROR) is ubiquitously expressed from the 16-cell to the tailbud stage 493 (Gomes et al., 2019a). In the tadpole, ROR expression is observed in the anterior region adjacent 494 to the brain, suggested to give rise to the future oral siphon in the adult (Gomes et al., 2019a; 495 Tolkin and Christiaen, 2016; Veeman et al., 2010). The ROR agonist SR1078 slightly reduced 
PSO area and trunk L/W ratio at $2 \mu \mathrm{M}$, whereas higher concentration affected almost all studied 497 endpoints (except tail length), indicating non-specific toxicity. This suggests that ROR might participate in PSO development but this should be confirmed by specific ROR knockdown.

499

500

501

502

503

504
It is known that the vertebrate pregnane $\mathrm{X}$ receptor $(\mathrm{PXR})$ is a member of the NR super-family which regulates transcription of genes involved in the metabolism and excretion of endogenous and exogenous toxic compounds (Fidler et al., 2012). PXR transcriptional targets in mammals include the cytochrome P450 (CYP) 2C and 3A enzymes, and transporters such as multidrug resistant protein (MDR, ABCB1) (Reschly et al., 2007). Those proteins in turn regulate, transport and metabolize xenobiotics, steroid hormones, and vitamins. In ascidians, such as Ciona intestinalis and Phallusia mammillata, genome encodes an orthologue of the vertebrate PXR and vitamin D receptor (VDR), denoted VDR/PXR (Yagi et al., 2003). Our previous study indicate that, in Phallusia, VDR/PXR is expressed in the brain region of embryos and larvae (Gomes et al., 2019a). As predicted, the current study shows significant changes in PSO development and trunk elongation after exposure to lindane and chlordane (PXR ligands according to Lemaire et al., 2004), and PXR agonists (rifampicin and SR12813). Functional inactivation of PXR in ascidians is now required to confirm the role of PXR in PSO development and trunk elongation.

Ascidians possess a single copy of the PPAR gene (Yagi et al., 2003), which is expressed in few cells within the ascidian brain, in the vicinity of the PSO (Gomes et al., 2019a). Interestingly, a synthetic ligand of PPAR $\gamma$, BADGE (Wright et al., 2000), showed significant effect on PSO development at $1-5 \mu \mathrm{M}$. Similar cocnentrations of BADGE also caused neurodevelopmental toxicity in an amphibian (Rhinella arenarum, $\left.\mathrm{EC}_{50}=0.5 \mu \mathrm{M}\right)($ Hutler et al., 2016). 
517 The majority of EDCs act primarily via steroid receptors (UNEP/WHO, 2013) but ascidians lack

518 steroid binding nuclear receptors such as ER or AR (Yagi et al., 2003). As expected, estradiol

519 benzoate (which binds only ER) was not toxic to ascidian embryos. The xenoestrogens DES,

520 4OHT and BPA all inhibited PSO development potentially via inhibition of the estrogen related

521 receptor (ERR) which is expressed in the PSO of the ascidian larva (Gomes et al., 2019b). Indeed,

522 even though ERR is an orphan NR, synthetic molecules such as DES and 4-OHT can directly bind 523 ascidian (Park et al., 2009) and vertebrate ERRs (Coward et al., 2001, Gibert et al., 2011), while

524 BPA binds vertebrate ERR $\gamma$ (Tohmé et al., 2014). Furthermore, ERR plays important roles in the 525 development of the vertebrate brain and sensory organs (Hermans-Borgmeyer et al., 2000; Lim et 526 al., 2015; Chen and Nathans, 2007). Together, our observations suggest that ERR is involved in 527 ascidian larval brain formation (see also Gomes et al., 2019b). The xenobiotics targeting ERR

528 (such as BPA, DES or 4OHT) are predicted to exert neurodevelopmental toxicity in ascidians. 529 However, since PSO development was affected also by other EDCs and other NR ligands, further 530 studies should clarify the role of ERR in PSO development.

\section{CONCLUSION}

533 Overall we conclude that Phallusia mammillata is a suitable and sensitive model for toxicity 534 screening. The ability to easily assess neural development in the transparent Phallusia larva also 535 offers to assess the impact on neurodevelopment of sublethal concentrations of toxicants shedding 536 light on potential mechanisms of teratogenicity or mode of actions of toxicants. The proposed 537 embryo/larval assay allows a fast and quantitative evaluation of teratogenic effects of xenobiotics 538 on ascidian embryo and a correlation with the extent of genotoxicity. 
539 Analysis of embryo phenotypes induced by different compounds indicate that severe 540 malformations resembling developmental delay are associated with genotoxicity. In contrast, 541 compounds like EDCs and NR ligands are impacting mostly neurodevelopmental endpoints. This

542 study sets the stage for quantitative analysis of embryo phenotypes that could be used to study not 543 only the teratogenicity of NR-targeting EDCs, but also the potential effects of pollutants that can 544 be dissolved in sea water.

545 Functional studies are needed to characterize Phallusia embryonic phenotypes observed after 546 activation or inhibition of NRs, and consequently compare these phenotypes with phenotypes 547 induced by a library of compounds, as a first step for performing predictive toxicology on marine 548 invertebrate organisms.

\section{Declaration of interest}

551 We declare that we have no financial or non-financial competing interests.

\section{Acknowledgements}

554 The authors would like to thank Laurent Gilletta from LBDV and the service aquariologie of 555 Centre de Ressources Biologiques of the Institut de la Mer de Villefranche (CRB - IMEV) that is 556 supported by EMBRC-France, and France BioImaging whose French state funds are managed by 557 the Agence Nationale de la Recherche (ANR) within the "Investissement d'Avenir" program 558 (ANR-10-INBS-02). The experiments reported in this study were financed by an ANR grant 559 (Marine-EmbryoTox project, ANR-14-OHRI-0009-01-1). Isa Gomes was funded by the French 
Ministry of Higher Education, of Research and Innovation and Doctoral School "Life Science Complexity" (ED515) for PhD scholarship. Ievgeniia Gazo thanks to the Ministry of Education, Youth and Sports of the Czech Republic: the CENAKVA project (LM2018099); project Reproductive and Genetic Procedures for Preserving Fish Biodiversity and Aquaculture (CZ.02.1.01/0.0/0.0/16_025/0007370), and the Czech Science Foundation GAČR 19-11140Y.

\section{REFERENCES}

Alzieu, C., 2000. Impact of tributyltin on marine invertebrates. Ecotoxicol. 9, 71-76.

Battistoni, M., Mercurio, S., Ficetola, G.F., Metruccio, F.C., Menegola, E., Pennati, R., 2018. The Ascidian Embryo Teratogenicity assay in Ciona intestinalis as a new teratological screening to test the mixture effect of the co-exposure to ethanol and fluconazole. Environ. Toxicol. Pharmacol. 57, 76-85. doi: 10.1016/j.etap.2017.11.014.

Bellas, J., Beiras, R., Mariño-Balsa, J.C., Fernández, N., 2005. Toxicity of organic compounds to marine invertebrate embryos and larvae: a comparison between the sea urchin embryogenesis bioassay and alternative test species. Ecotoxicol., 14(3), 337-353.

Bentivegna, C.S., Piatkowski, T., 1998. Effects of tributyltin on medaka (Oryzias latipes) embryos at different stages of development. Aquat. Toxicol. 44, 117-128.

Castro, L.F., Lima, D., Machado, A., Melo, C., Hiromori, Y., Nishikawa, J., Nakanishi, T., Reis-Henriques, M.A., Santos, M.M., 2007. Imposex induction is mediated through the Retinoid X Receptor signalling pathway in the neogastropod Nucella lapillus. Aquat. Toxicol. 85(1), 57-66.

Chen, J., Nathans, J., 2007. Estrogen-Related Receptor $\beta$ /NR3B2 controls epithelial cell fate and endolymph production by the Stria Vascularis. Dev. Cell 13, 325-337. doi 10.1016/j.devcel.2007.07.011.

Chenevert, J., Roca, M., Besnardeau, L., Ruggiero, A., Nabi, D., McDougall, A., Copley, R.R., Christians, E., Castagnetti S., 2020. The spindle assembly checkpoint functions during early development in non-chordate embryos. Cells 9(5), E1087. doi: 10.3390/cells9051087.

Chiarelli, R., Martino, C., Roccheri, M.C., 2019. Cadmium stress effects indicating marine pollution in different species of sea urchin employed as environmental bioindicators. Cell Stress Chaperones 24(4), 675-687. doi: 10.1007/s12192-019-01010-1.

Coward, P., Lee, D., Hull, M.V., Lehmann, J.M., 2001. 4-Hydroxytamoxifen binds to and deactivates the estrogen-related receptor gamma. Proc. Natl. Acad. Sci. USA 98(15), 8880-4. 
Delsuc, F., Brinkmann, H., Chourrout, D., Philippe, H., 2006. Tunicates and not cephalochordates are the closest living relatives of vertebrates. Nature 439(7079), 965-968.

Desbiolles, F., Malleret, L., Tiliacos, C., Wong-Wah-Chung, P., Laffont-Schwob, I., 2018. Occurrence and ecotoxicological assessment of pharmaceuticals: Is there a risk for the Mediterranean aquatic environment? Sci. Total. Environ. 639, 1334-1348. doi: 10.1016/j.scitotenv.2018.04.351.

Dixon, D.R., Pruski, A.M., Dixon L.R.J., Jha, A.N., 2002. Marine invertebrate ecogenotoxicology: a methodological overview. Mutagenesis 17 (6), 495-507.

Dumollard, R., Gazo, I., Gomes, I.D.L., Besnardeau, L., McDougall, A., 2017. Ascidians: An Emerging Marine Model for Drug Discovery and Screening. Curr. Top. Med. Chem. 17(18), 2056-2066. doi: 10.2174/1568026617666170130104922.

Ekins, S., Reschly, E.J., Hagey, L.R., Krasowski, M.D., 2008. Evolution of pharmacologic specificity in the pregnane X receptor. BMC Evol. Biol. 8, 103. doi: 10.1186/1471-2148-8103.

Esner, M., Meyenhofer, F., Bickle, M., 2018. Live-cell high content screening in drug development. Methods Mol. Biol. 1683, 149-164. doi: 10.1007/978-1-4939-7357-6_10.

Fidler, A.E., Holland, P.T., Reschly, E.J., Ekins, S., Krasowski, M.D., 2012. Activation of a tunicate (Ciona intestinalis) xenobiotic receptor orthologue by both natural toxins and synthetic toxicants. Toxicon. 59(2), 365-372. doi: 10.1016/j.toxicon.2011.12.008.

Fujiwara, S., Kawamura, K., 2003. Acquisition of retinoic acid signaling pathway and innovation of the chordate body plan. Zool. Sci. 20, 809-818.

Gallo, A., Tosti, E., 2013. Adverse effect of antifouling compounds on the reproductive mechanisms of the ascidian Ciona intestinalis. Mar. Drugs, 11(9), 3554-3568. https://doi.org/10.3390/md11093554

Gallo, A., Tosti, E., 2015. The ascidian Ciona intestinalis as model organism for ecotoxicological bioassays. J. Marine Sci. Res. Dev. 5, e138. doi:10.4172/2155$9910.1000 \mathrm{e} 138$

Gibert, Y., Sassi-Messai, S., Fini, J.B., Bernard, L., Zalko, D., Cravedi, J.P., Balaguer, P., Andersson-Lendahl, M., Demeneix, B., Laudet, V., 2011. Bisphenol A induces otolith malformations during vertebrate embryogenesis. BMC Dev. Biol. 11, 4. doi: 10.1186/1471213X-11-4.

Gomes, I.D.L., Gazo, I., Besnardeau, L., Hebras, C., McDougall, A., Dumollard, R., 2019a. Potential roles of nuclear receptors in mediating neurodevelopmental toxicity of known endocrine-disrupting chemicals in ascidian embryos. Mol. Reprod. Dev. 86, 1333-1347. doi: 10.1002/mrd.23219. 
Gomes, I.D.L., Gazo, I., Nabi, D., Besnardeau, L., Hebras, C., McDougall, A., Dumollard R., 2019b. Bisphenols disrupt differentiation of the pigmented cells during larval brain formation in the ascidian. Aquat. Toxicol. 216, 105314. doi: 10.1016/j.aquatox.2019.

Häder, D.P., Helbling, E.W., Williamson, C.E., Worrest, R.C., 2011. Effects of UV radiation on aquatic ecosystems and interactions with climate change. Photochem. Photobiol. Sci. 10, 242-260.

Hermans-Borgmeyer, I., Süsens, U., Borgmeyer, U., 2000. Developmental expression of the estrogen receptor-related receptor gamma in the nervous system during mouse embryogenesis. Mech. Dev. 97(1-2), 197-199.

Holland, L.Z., Holland, N.D., 1999. Chordate origins of the vertebrate central nervous system. Curr. Opin. Neurobiol. 9(5), 596-602.

Hudson, C., 2016. The central nervous system of ascidian larvae. Wiley. Interdiscip. Rev. Dev. Biol. 5(5), 538-561. doi: 10.1002/wdev.239.

Hutler, W.I., Svartz, G.V., Aronzon, C.M., Pérez Coll, C., 2016. Developmental toxicity of bisphenol A diglycidyl ether (epoxide resin badge) during the early life cycle of a native amphibian species. Environ. Toxicol. Chem. 35, 3031-3038. doi:10.1002/etc.3491.

Ishii, H., Shirai, T., Makino, C., Nishikata, T., 2014. Mitochondrial inhibitor sodium azide inhibits the reorganization of mitochondria-rich cytoplasm and the establishment of the anteroposterior axis in ascidian embryo. Dev. Growth. Differ. 56(2), 175-188. doi: 10.1111/dgd.12117.

Kanda, M., Wada, H., Fujiwara, S., 2009. Epidermal expression of Hox1 is directly activated by retinoic acid in the Ciona intestinalis embryo. Dev. Biol. 335(2), 454-463. doi: 10.1016/j.ydbio.2009.09.027.

Kirkland, D., Kasper, P., Martus, H. J., Müller, L., van Benthem, J., Madia, F., Corvi, R., 2016. Updated recommended lists of genotoxic and non-genotoxic chemicals for assessment of the performance of new or improved genotoxicity tests. Mutat. Res. Genet. Toxicol. Environ. Mutagen. 795, $7-30$.

Le Bihanic, F., Di Bucchianico, S., Karlsson, H.L., Dreij, K., 2016. In vivo micronucleus screening in zebrafish by flow cytometry. Mutagenesis 31(6), 643-653.

le Maire, A., Grimaldi, M., Roecklin, D., Dagnino, S., Vivat-Hannah, V., Balaguer, P., Bourguet, W., 2009. Activation of RXR-PPAR heterodimers by organotin environmental endocrine disruptors. EMBO Rep. 10, 367-373.

Lee, L.M., Leung, C.Y., Tang, W.W., Choi, H.L., Leung, Y.C., McCaffery, P.J., Wang, C.C., Woolf, A.S., Shum, A.S., 2012. A paradoxical teratogenic mechanism for retinoic acid. Proc. Natl. Acad. Sci. USA 109(34), 13668-13673. doi: 10.1073/pnas.1200872109. 
Lemaire, G., de Sousa, G., Rahmani, R., 2004. A PXR reporter gene assay in a stable cell culture system: CYP3A4 and CYP2B6 induction by pesticides. Biochem. Pharmacol. 68(12), 2347-2358.

Lim, J., Choi, H.S., Choi, H.J., 2015. Estrogen-related receptor gamma regulates dopaminergic neuronal phenotype by activating GSK3 $\beta /$ NFAT signaling in SH-SY5Y cells. J Neurochem. 133(4), 544-557. doi: 10.1111/jnc.13085.

Mangelsdorf, D.J., Evans, R.M., 1995. The RXR heterodimers and orphan receptors. Cell 83, 841-850

Matsushima, A., Ryan, K., Shimohigashi, Y., Meinertzhagen, I.A., 2013. An endocrine disruptor, bisphenol A, affects development in the protochordate Ciona intestinalis: hatching rates and swimming behavior alter in a dose-dependent manner. Environ. Pollut. 173, 257-263. doi: 10.1016/j.envpol.2012.10.015.

Matthiessen, P., 2019. The impact of organotin pollution on aquatic invertebrate communities - are molluscs the only group whose populations have been affected? Env. Sci. Heal. 11, 1320. doi: 10.1016/j.coesh.2019.06.003

Mnif, W., Hassine, A.I., Bouaziz, A., Bartegi, A., Thomas, O., Roig, B., 2011. Effect of endocrine disruptor pesticides: a review. Int. J. Environ. Res. Public Health. 8(6), 2265-2303. doi: 10.3390/ijerph8062265.

Nagatomo, K., Ishibashi, T., Satou, Y., Satoh, N., Fujiwara, S., 2003. Retinoic acid affects gene expression and morphogenesis without upregulating the retinoic acid receptor in the ascidian Ciona Intestinalis. Mech. Dev.120 (3), 363-372.

Nishikawa, J., Mamiya, S., Kanayama, T., Nishikawa, T., Shiraishi, F., Horiguchi, T., 2004. Involvement of the retinoid $\mathrm{X}$ receptor in the development of imposex caused by organotins in gastropods. Environ. Sci. Technol. 38(23), 6271-6276.

OECD (2016), Test No. 473: In Vitro Mammalian Chromosomal Aberration Test, OECD Guidelines for the Testing of Chemicals, Section 4, OECD Publishing, Paris, https://doi.org/10.1787/9789264264649-en.

OECD (2016), Test No. 487: In Vitro Mammalian Cell Micronucleus Test, OECD Guidelines for the Testing of Chemicals, Section 4, OECD Publishing, Paris, https://doi.org/10.1787/9789264264861-en.

OECD (2016), Test No. 489: In Vivo Mammalian Alkaline Comet Assay, OECD Guidelines for the Testing of Chemicals, Section 4, OECD Publishing, Paris, https://doi.org/10.1787/9789264264885-en.

Oyanagi, K., Tashiro, T., Negishi, T., 2015. Cell-type-specific and differentiation-statusdependent variations in cytotoxicity of tributyltin in cultured rat cerebral neurons and astrocytes. J. Toxicol. Sci. 40(4), 459-468. doi: 10.2131/jts.40.459. 
Park, W., Kim, G.J., Choi, H.S., Vanacker, J.M., Sohn, Y.C., 2009. Conserved properties of a urochordate estrogen receptor-related receptor (ERR) with mammalian ERRalpha. Biochim. Biophys. Acta. 1789(2), 125-134. doi: 10.1016/j.bbagrm.2008.08.011. Venkataramanan, R., Krasowski, M.D., 2007. Functional evolution of the vitamin D and pregnane X receptors. BMC Evol. Biol. 7, 222.

Saotome, K., Sofuni, T., Hayashi, M., 1999. A micronucleus assay in sea urchin embryos. Mutat. Res. 446(1), 121-127. Hebras, C., Le Nguyen, N., Paix, A., 2011. Embryological methods in ascidians: the Villefranche-sur-Mer protocols. Methods Mol. Biol. 770, 365-400.

Sarkar, A., Ray, D., Shrivastava, A.N., Sarker, S., 2006. Molecular Biomarkers: their significance and application in marine pollution monitoring. Ecotoxicology 15(4), 333-340. doi:10.1007/s10646-006-0069-1.

Takamura, K., 1998. Nervous network in larvae of the ascidian Ciona intestinalis. Dev. Genes. Evol. 208, 1-8.

Tohmé, M., Prud'homme, S.M., Boulahtouf, A., Samarut, E., Brunet, F., Bernard, L., Bourguet, W., Gibert, Y., Balaguer, P., Laudet, V., 2014. Estrogen-related receptor $\gamma$ is an in vivo receptor of bisphenol A. FASEB J. 28(7), 3124-3133. doi: 10.1096/fj.13-240465.

Tolkin, T., Christiaen, L., 2016. Rewiring of an ancestral Tbx1/10-Ebf-Mrf network for

pharyngeal muscle specification in distinct embryonic lineages. Development 143(20), 38523862. https://doi.org/10.1242/dev.136267

UNEP/WHO, 2013. World Health Organization, United Nations Environment Programme (WHO-UNEP). In: Bergman, A., Heindel, J.J., Jobling, S., Kidd, K.A., Zoeller, R.T. (Eds.), State of the Science of Endocrine Disrupting Chemicals. Available at: http://www.who.int/ceh/publications/endocrine/en/index.htm.

Urushitani, H., Katsu, Y., Kagechika, H., Sousa, A.C.A., Barroso, C.M., Ohta, Y., Shiraishi, H., Iguchi, T., Horiguchi, T. 2018. Characterization and comparison of transcriptional activities of the retinoid $\mathrm{X}$ receptors by various organotin compounds in three prosobranch gastropods; Thais clavigera, Nucella lapillus and Babylonia japonica. Aquat. Toxicol. 199, 103-115. doi: 10.1016/j.aquatox.2018.03.029.

Veeman, M.T., Newman-Smith, E., El-Nachef, D., Smith, W.C., 2010. The ascidian mouth opening is derived from the anterior neuropore: Reassessing the mouth/neural tube relationship in chordate evolution. Dev. Biol. 344(1), 138-149. https://doi.org/10.1016/j.ydbio.2010.04.028

Weyermann, J., Lochmann, D., Zimmer, A., 2005. A practical note on the use of cytotoxicity assays. Int. J. Pharm. 288(2), 369-376. 
Wright, H.M., Clish, C.B., Mikami, T., Hauser, S., Yanagi, K., Hiramatsu, R., Serhan, C.N., Spiegelman, B.M., 2000. A synthetic antagonist for the peroxisome proliferator-activated receptor gamma inhibits adipocyte differentiation. J. Biol. Chem. 275(3), 1873-1877. Y., Satoh, N., 2003. A genomewide survey of developmentally relevant genes in Ciona intestinalis. III. Genes for Fox, ETS, nuclear receptors and NFkappaB. Dev. Genes Evol. 213, 235-244. doi 10.1007/s00427-003-0322-z.

Yamada, A., Nishida, H., 2014. Control of the number of cell division rounds in distinct tissues during ascidian embryogenesis. Dev. Growth Differ. 56(5), 376-386. doi: 10.1111/dgd.12141. embryos (Chordata, Tunicata) as model organisms for testing coastal pollutant toxicity. Inverteb. Surv. J., 6(1 (Suppl)), S29-S34. 2018. Retinoic acid signaling and neurogenic niche regulation in the developing peripheral nervous system of the cephalochordate amphioxus. Cell Mol. Life Sci. 75(13), 2407-2429. doi: 10.1007/s00018-017-2734-3. 
Table 1. List of chemicals used for toxicity screening and concentrations analyzed in the current study, listed in the order presented on figures 2 - 4. The LOEC is the lowest tested concentration (experimental) that is significantly different from the control as determined by one or several endpoints (Kruskal-Wallis test, $\mathrm{P}<0.05$ ). Last column mention the affected endpoint at LOEC.

\begin{tabular}{|c|c|c|c|}
\hline Chemical name & $\begin{array}{l}\text { Doses assessed in } \\
\text { the current study }\end{array}$ & LOEC $^{1}$ & Affected endpoints at LOEC \\
\hline Sodium azide & $0.1-2.5 \mathrm{mM}$ & $1 \mathrm{mM}$ & $\begin{array}{l}\text { PSO }^{2} \text { area, PSO distance, Trunk } \\
\text { L/W ratio }{ }^{3} \text {, Tail length }\end{array}$ \\
\hline Tributyltin & $10-50 \mathrm{nM}$ & $10 \mathrm{nM}$ & $\begin{array}{l}\text { PSO area, PSO distance, Trunk } \\
\text { L/W ratio }\end{array}$ \\
\hline Etoposide & $50 \mathrm{nM}-10 \mu \mathrm{M}$ & $50 \mathrm{nM}$ & $\begin{array}{l}\text { PSO area, PSO distance, Trunk } \\
\mathrm{L} / \mathrm{W} \text { ratio }\end{array}$ \\
\hline Mitomycin C & $10-60 \mu \mathrm{M}$ & $10 \mu \mathrm{M}$ & $\begin{array}{l}\text { PSO distance, Trunk L/W ratio, } \\
\text { Tail length }\end{array}$ \\
\hline$\gamma$-BHC (Lindane) & $2.5-20 \mu \mathrm{M}$ & $10 \mu \mathrm{M}$ & PSO distance, Trunk L/W ratio \\
\hline Atrazine & $1-70 \mu \mathrm{M}$ & $50 \mu \mathrm{M}$ & PSO distance, Trunk L/W ratio \\
\hline Bisphenol A (BPA) & $1-50 \mu \mathrm{M}$ & $\begin{array}{l}1 \mu \mathrm{M} \\
(\text { Gomes et al., } \\
2019 \mathrm{~b})\end{array}$ & PSO area, PSO distance \\
\hline cis/trans-Chlordane & $10-50 \mu \mathrm{M}$ & $10 \mu \mathrm{M}$ & PSO area, PSO distance \\
\hline Chlorpyrifos & $10-100 \mu \mathrm{M}$ & $10 \mu \mathrm{M}$ & PSO area \\
\hline $\begin{array}{l}\text { Estradiol benzoate } \\
\text { (E2B) }\end{array}$ & $5-10 \mu \mathrm{M}$ & $\mathrm{ND}^{4}$ & $\mathrm{ND}^{4}$ \\
\hline
\end{tabular}




\begin{tabular}{|c|c|c|c|}
\hline $\begin{array}{l}\text { ATRA } \\
\text { (all trans retinoic } \\
\text { acid) }\end{array}$ & $0.01-5 \mu \mathrm{M}$ & $0.1 \mu \mathrm{M}$ & $\begin{array}{l}\text { \% embryos with palps, Trunk L/W } \\
\text { ratio }\end{array}$ \\
\hline BMS493 & $1-5 \mu \mathrm{M}$ & $3 \mu \mathrm{M}$ & $\begin{array}{l}\text { PSO area, \% embryos with palps, } \\
\text { Tail length }\end{array}$ \\
\hline UVI3003 & $0.1-2 \mu \mathrm{M}$ & $1 \mu \mathrm{M}$ & PSO area, \% embryos with palps \\
\hline $\begin{array}{l}\text { 4-Hydroxytamoxifen } \\
\text { (4HT) }\end{array}$ & $1-50 \mu \mathrm{M}$ & $5 \mu \mathrm{M}$ & PSO distance \\
\hline $\begin{array}{l}\text { Diethylstilbestrol } \\
\text { (DES) }\end{array}$ & $0.1-25 \mu \mathrm{M}$ & $1 \mu \mathrm{M}$ & $\begin{array}{l}\mathrm{PSO} \text { area, } \mathrm{PSO} \text { distance, Trunk } \\
\mathrm{L} / \mathrm{W} \text { ratio }\end{array}$ \\
\hline Rifampicin & $10-100 \mu \mathrm{M}$ & $50 \mu \mathrm{M}$ & PSO distance, Trunk L/W ratio \\
\hline SR 1078 & $0.1-5 \mu \mathrm{M}$ & $2 \mu \mathrm{M}$ & PSO area \\
\hline BADGE & $1-100 \mu \mathrm{M}$ & $1 \mu \mathrm{M}$ & Trunk L/W ratio \\
\hline SR 12813 & $1.5-10 \mu \mathrm{M}$ & $3 \mu \mathrm{M}$ & $\begin{array}{l}\mathrm{PSO} \text { area, } \mathrm{PSO} \text { distance, Trunk } \\
\mathrm{L} / \mathrm{W} \text { ratio }\end{array}$ \\
\hline
\end{tabular}

${ }^{1}$ LOEC - the lowest tested concentration (experimental) that is significantly different from the control as determined by one or several endpoints (Kruskal-Wallis test, $\mathrm{P}<0.05$ ).

${ }^{2} \mathrm{PSO}-$ pigmented sensory organs

${ }^{3}$ Trunk L/W ratio - trunk length / width ratio

${ }^{4} \mathrm{ND}$ - not determined 
Figure 1. Changes of morphological parameters during embryonic development (between stage 22 and stage 26). A. The measured endpoints are summarized in the radar chart depicting normalized values (normalized to stage 26 values): ocellus (Oc) + otolith $(\mathrm{Ot})$ area $\left(\mu \mathrm{m}^{2}\right)$; Oc/Ot distance $(\mu \mathrm{m})$; percentage of embryos with palps $(\%)$; trunk L/W (length/width) ratio; tail length $(\mu \mathrm{m})$. Measurement of all parameters was performed for min $\mathrm{N}=50$ embryos. Asterisks indicate significant difference compared to the control (Kruskal-Wallis test, $\mathrm{P}<0.05$ ). B. Trunk region at $18 \mathrm{hpf}$ (stage 22). Black arrow shows formation of ocellus (Oc). C. Trunk region at $19 \mathrm{hpf}$ (stage 23). Black arrow shows formation of ocellus (Oc), dark grey arrow shows formation of otolith (Ot) and separation of two pigmented sensory organs (PSO) at stage 23. White arrow indicates formation of palps at stage $23 \mathbf{D}$. Trunk region at $20 \mathrm{hpf}$ (stage 24). E. Trunk region at $21 \mathrm{hpf}$ (stage 25). F. Trunk region at $22 \mathrm{hpf}$ (stage 26). Scale bars correspond to $20 \mu \mathrm{m}$
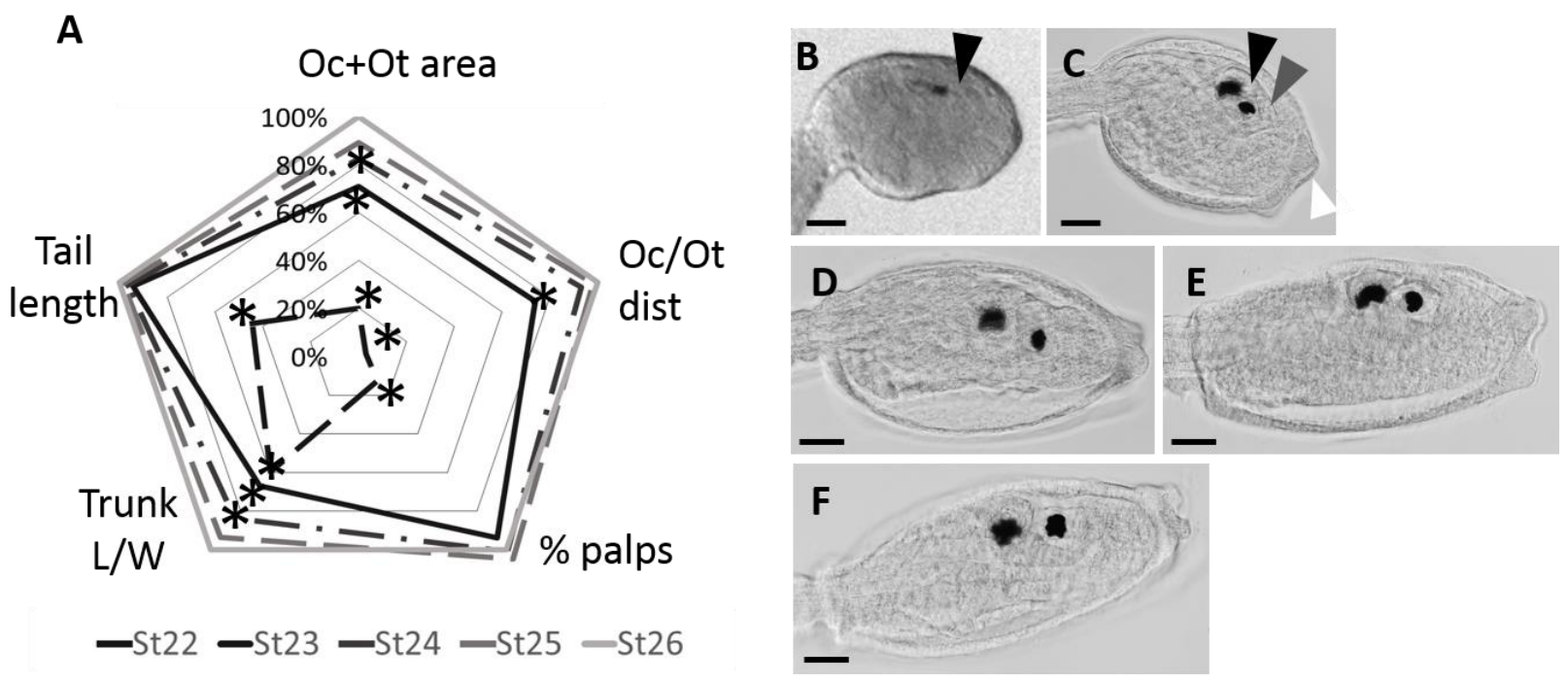
Table 2. Changes of morphological parameters during embryonic development. (between stage 22 and stage 26). The mean values $\pm \mathrm{SD}$ are presented. $\mathrm{N}$ is the number of embryos assessed at each stage. The line "St26 controls-2015-209" shows average values of morphological parameters from all cultures performed in this study.

\begin{tabular}{|l|l|l|l|l|l|l|}
\hline $\begin{array}{l}\text { Stage of } \\
\text { embryo } \\
\text { development }\end{array}$ & $\mathrm{N}$ & $\begin{array}{l}\text { PSO area, } \\
\mu \mathrm{m}^{2}\end{array}$ & $\begin{array}{l}\text { PSO distance, } \\
\mu \mathrm{m}\end{array}$ & Palps, \% & $\begin{array}{l}\text { Trunk L/W } \\
\text { ratio }^{2}\end{array}$ & $\begin{array}{l}\text { Tail length, } \\
\mu \mathrm{m}\end{array}$ \\
\hline Stage 22 & 49 & $72 \pm 24$ & $0,8 \pm 3$ & 12 & $1,3 \pm 0,1$ & $237 \pm 24$ \\
\hline Stage 23 & 47 & $253 \pm 64$ & $18 \pm 8$ & 89 & $1,4 \pm 0,1$ & $506 \pm 37$ \\
\hline Stage 24 & 49 & $294 \pm 47$ & $23 \pm 6$ & 96 & $1,8 \pm 0,3$ & $516 \pm 173$ \\
\hline Stage 25 & 46 & $317 \pm 41$ & $24 \pm 4$ & 100 & $1,9 \pm 0,2$ & $527 \pm 146$ \\
\hline Stage 26 & 75 & $320 \pm 47$ & $24 \pm 7$ & 100 & $2 \pm 0,2$ & $535 \pm 116$ \\
\hline $\begin{array}{l}\text { Stage 26, } \\
\text { controls 2015- } \\
\text { 2019 }\end{array}$ & 4903 & $292 \pm 142$ & $20 \pm 11$ & $92 \pm 3.2$ & $2.6 \pm 1.5$ & $483 \pm 162$ \\
\hline
\end{tabular}

${ }^{1}$ Palps, $\%$ - the percentage embryos with palps;

${ }^{2}$ Trunk L/W ratio - trunk length / width ratio 
Table 3. Morphometric analysis of phenotypes observed in Phallusia mammillata larvae exposed to toxicants. N shows the number of embryos analyzed. The table summarize the following endpoints: ocellus (Oc) + otolith (Ot) area ( $\mu \mathrm{m} 2)$; Oc/Ot distance $(\mu \mathrm{m})$; percentage of embryos with palps (\%); trunk L/W (length/width) ratio; tail length $(\mu \mathrm{m})$. All measurements are performed at $22 \mathrm{hpf}$. Data presented as means \pm S.E and as $\%$ to the control. Asterisks indicate significant difference compared to the control (Kruskal-Wallis test, $\mathrm{P}<0.05)$. SA indicate sodium azide ; TBT - tributyltin.

\begin{tabular}{|c|c|c|c|c|c|c|c|c|c|c|c|}
\hline Treatment & $\mathrm{N}$ & $\begin{array}{c}\text { Oc/Ot area, } \\
\mu \mathrm{m}^{2}, \text { mean } \pm \\
\text { S.E. }\end{array}$ & $\begin{array}{l}\text { Oc/Ot } \\
\text { area, } \% \\
\text { to the } \\
\text { control }\end{array}$ & $\begin{array}{l}\text { Oc/Ot distance, } \\
\mu m, \text { mean } \pm S . E \text {. }\end{array}$ & $\begin{array}{l}\text { Oc/Ot } \\
\text { distance } \\
\% \text { to the } \\
\text { control }\end{array}$ & $\begin{array}{c}\% \text { palps, } \\
\text { means } \pm \text { S.E. }\end{array}$ & $\begin{array}{l}\text { Palps } \% \\
\text { to the } \\
\text { control }\end{array}$ & $\begin{array}{l}\text { Trunk L/W } \\
\text { ratio, means L } \\
\quad \pm \text { S.E. }\end{array}$ & $\begin{array}{l}\text { Trunk } \\
\text { L/W \% to } \\
\text { the } \\
\text { control }\end{array}$ & $\begin{array}{l}\text { Tail length, } \mu \mathrm{m} \text {, } \\
\text { means } \pm S . E \text {. }\end{array}$ & $\begin{array}{l}\text { Tail } \\
\text { length } \% \\
\text { to the } \\
\text { control }\end{array}$ \\
\hline control & 322 & $362.9 \pm 8.1-$ & & $19.7 \pm 0.6$ & & $91.7 \pm 3.2-$ & & $2.3 \pm 0.03-$ & & $550.1 \pm 4.6$ & \\
\hline SA 100uM & 317 & $355.3 \pm 8.6$ & $93 \%$ & $19.4 \pm 0.6$ & $95 \%$ & $90.1 \pm 2.9$ & $100 \%$ & $2.3 \pm 0.03$ & $94 \%$ & $531.1 \pm 4.7$ & $97 \%$ \\
\hline SA $1 \mathrm{mM}$ & 151 & $268 \pm 16.6$ * & $58 \%$ & $10.1 \pm 0.9$ * & $37 \%$ & $35.6 \pm 31.5$ & $37 \%$ & $1.7 \pm 0.03$ * & $67 \%$ & $425.3 \pm 18.6$ * & $66 \%$ \\
\hline $\mathrm{SA} 2.5 \mathrm{mM}$ & 115 & $300.2 \pm 19.2$ * & $56 \%$ & $4.1 \pm 0.9$ * & $19 \%$ & $3.8 \pm 3.8$ * & $6 \%$ & $1.2 \pm 0.01$ * & $57 \%$ & $339.2 \pm 11.2$ * & $58 \%$ \\
\hline control & 120 & $314.1 \pm 12.4-$ & & $21.7 \pm 1.1-$ & & $93.7 \pm 3.7-$ & & $2.2 \pm 0.04$ & & $510.9 \pm 12.2$ & \\
\hline TBT 10nM & 106 & $186.8 \pm 13.5^{*}$ & $60 \%$ & $10.5 \pm 1.2$ * & $48 \%$ & $66.1 \pm 14.5$ & $72 \%$ & $1.6 \pm 0.05$ * & $73 \%$ & $477.7 \pm 14.1$ & $99 \%$ \\
\hline TBT 20nM & 133 & $164.3 \pm 12.1$ * & $47 \%$ & $9.4 \pm 1$ * & $38 \%$ & $46.4 \pm 17.3$ & $50 \%$ & $1.6 \pm 0.05$ * & $70 \%$ & $443.6 \pm 13.3$ & $79 \%$ \\
\hline TBT 50nM & 122 & $40.8 \pm 7.5^{*}$ & $10 \%$ & $1.2 \pm 0.5$ * & $4 \%$ & $13.3 \pm 12.3^{*}$ & $14 \%$ & $1.3 \pm 0.03$ * & $54 \%$ & $302.3 \pm 13.3$ * & $49 \%$ \\
\hline control & 211 & $298.1 \pm 6.5-$ & & $25.6 \pm 0.6-$ & & $98.8 \pm 1.2$ & & $2.2 \pm 0.02$ & & $433.8 \pm 18.8$ & \\
\hline Etoposide 50nM & 168 & $252.4 \pm 6.3$ * & $95 \%$ & $21.3 \pm 0.8$ * & $80 \%$ & $98.8 \pm 0.6$ & $100 \%$ & $2 \pm 0.02$ * & $92 \%$ & $428.9 \pm 20.3$ & $97 \%$ \\
\hline Etoposide $75 \mathrm{nM}$ & 116 & $221.3 \pm 7.4$ * & $86 \%$ & $14.6 \pm 1.1$ * & $58 \%$ & $70.9 \pm 16.9$ & $73 \%$ & $1.7 \pm 0.03$ * & $86 \%$ & $463.7 \pm 19.2$ & $92 \%$ \\
\hline Etoposide $100 \mathrm{nM}$ & 139 & $120.8 \pm 7.7^{*}$ & $44 \%$ & $4.2 \pm 0.7$ * & $18 \%$ & $20.1 \pm 18.7^{*}$ & $21 \%$ & $1.3 \pm 0.02$ * & $63 \%$ & $253.2 \pm 16.1$ * & $56 \%$ \\
\hline control & 410 & $366.3 \pm 5.4$ & & $20.6 \pm 0.5-$ & & $93.6 \pm 1.5$ & & $2.4 \pm 0.01$ & & $443.9 \pm 1.5$ & \\
\hline Mitomycin C $10 \mu \mathrm{M}$ & 361 & $340.8 \pm 6.7$ & $95 \%$ & $15.7 \pm 0.7$ * & $81 \%$ & $56.5 \pm 11.7$ & $41 \%$ & $1.5 \pm 0.01$ * & $56 \%$ & $317.4 \pm 4.7$ * & $93 \%$ \\
\hline Mitomycin C $40 \mu \mathrm{M}$ & 284 & $285.6 \pm 10.3$ & $96 \%$ & $10.3 \pm 1$ * & $44 \%$ & $12.4 \pm 6.2$ * & $15 \%$ & $1.3 \pm 0.01$ * & $46 \%$ & $234.4 \pm 5.8$ * & $71 \%$ \\
\hline Mitomycin C $60 \mu \mathrm{M}$ & 165 & $226 \pm 13.4$ * & $62 \%$ & $4.4 \pm 0.9$ * & $32 \%$ & $0.3 \pm 0.3$ * & $0 \%$ & $1.2 \pm 0.01$ * & $44 \%$ & $421.5 \pm 2.6$ * & $59 \%$ \\
\hline
\end{tabular}


Figure 2. The percentage of normal (light grey), malformed (dark grey) and undeveloped (black) embryos in the sodium azide (SA) $2.5 \mathrm{mM}$, etoposide (Et) $100 \mathrm{nM}$ and $10 \mu \mathrm{M}$, mitomycin $60 \mu \mathrm{M}$, tributyltin (TBT) $50 \mathrm{nM}$. Data are presented as means \pm SEM.

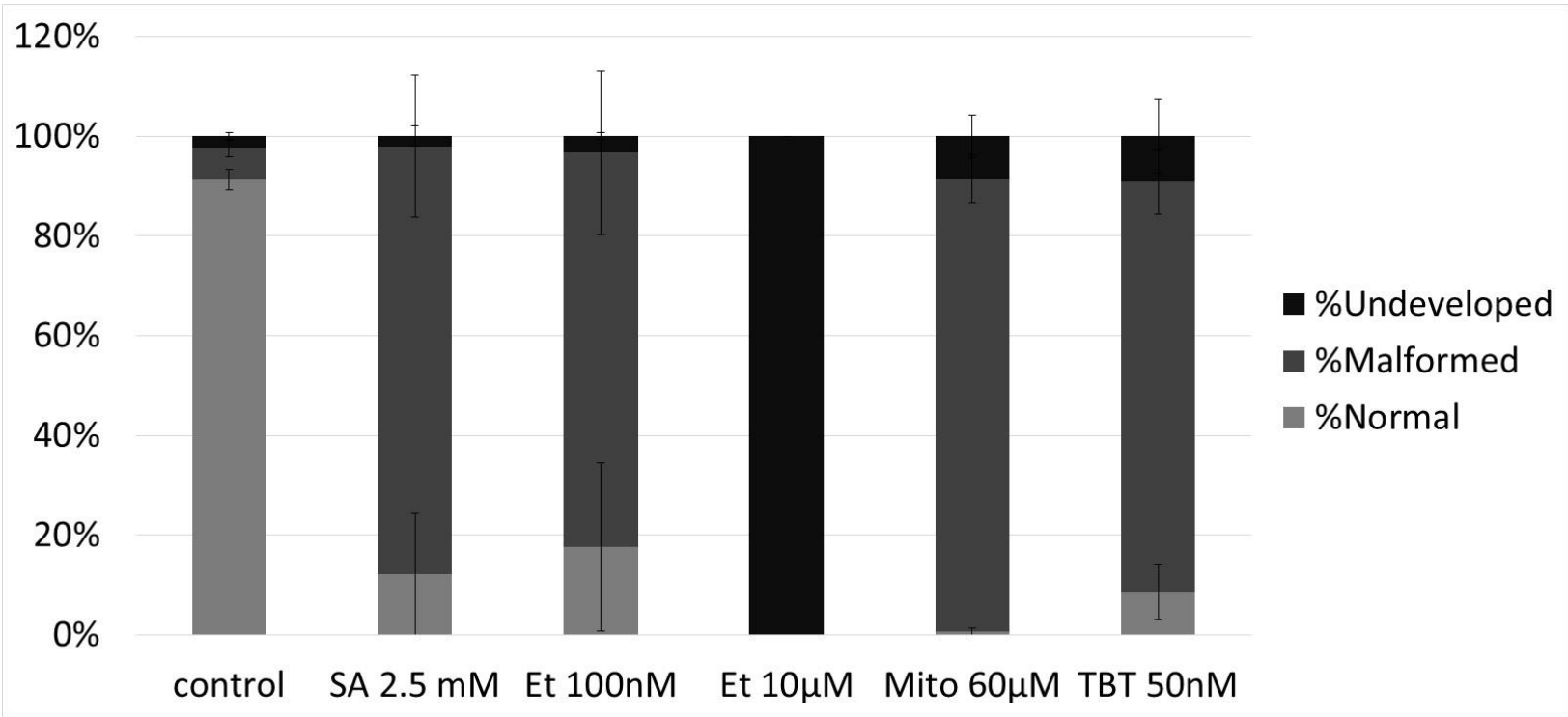


Table 4. Morphometric analysis of phenotypes observed in Phallusia mammillata larvae exposed to EDCs. N shows the number of embryos analyzed. The table summarize the following endpoints: ocellus (Oc) + otolith (Ot) area ( $\mu \mathrm{m} 2)$; Oc/Ot distance $(\mu \mathrm{m})$; percentage of embryos with palps (\%); trunk L/W (length/width) ratio; tail length $(\mu \mathrm{m})$. All measurements are performed at $22 \mathrm{hpf}$. Data presented as means \pm S.E and as $\%$ to the control. Asterisks indicate significant difference compared to the control (Kruskal-Wallis test, $\mathrm{P}<0.05)$. BPA indicate bisphenol A ; E2B - estradiol benzoate.

\begin{tabular}{|c|c|c|c|c|c|c|c|c|c|c|c|}
\hline Treatment & $\mathrm{N}$ & $\begin{array}{l}\text { Oc/Ot area, } \\
\mu \mathrm{m}^{2} \text {, mean } \pm \\
\text { S.E. }\end{array}$ & $\begin{array}{l}\text { Oc/Ot area } \\
\% \text { to the } \\
\text { control }\end{array}$ & $\begin{array}{c}\text { Oc/Ot } \\
\text { distance, } \mu \mathrm{m} \text {, } \\
\text { mean } \pm \text { S.E. }\end{array}$ & $\begin{array}{c}\text { Oc/Ot } \\
\text { distance } \% \\
\text { to the } \\
\text { control }\end{array}$ & $\begin{array}{c}\% \text { palps, } \\
\text { means } \pm \text { S.E. }\end{array}$ & $\begin{array}{l}\text { Palps } \% \text { to } \\
\text { the control }\end{array}$ & $\begin{array}{l}\text { Trunk L/W } \\
\text { ratio, means } \\
\pm S . E .\end{array}$ & $\begin{array}{l}\text { Trunk L/W } \\
\% \text { to the } \\
\text { control }\end{array}$ & $\begin{array}{c}\text { Tail length, } \\
\mu \mathrm{m}, \text { means } \pm \\
\text { S.E. }\end{array}$ & $\begin{array}{l}\text { Tail length } \\
\% \text { to the } \\
\text { control }\end{array}$ \\
\hline control & 112 & $321.1 \pm 14.8$ & & $20.3 \pm 1.2$ & & $80.1 \pm 1.6$ & & $2.2 \pm 0.04$ & & $499.5 \pm 12.5$ & \\
\hline Lindane $10 \mu \mathrm{M}$ & 136 & $286.7 \pm 12.2$ & $92 \%$ & $12.4 \pm 1.1 *$ & $62 \%$ & $68 \pm 4.5$ & $85 \%$ & $1.7 \pm 0.02 *$ & $77 \%$ & $489 \pm 8$ & $95 \%$ \\
\hline Lindane $15 \mu \mathrm{M}$ & 139 & $224.4 \pm 12.2$ * & $71 \%$ & $8.8 \pm 1$ * & $44 \%$ & $60.6 \pm 11.1$ & $75 \%$ & $1.5 \pm 0.02$ * & $70 \%$ & $476.2 \pm 5.4$ & $92 \%$ \\
\hline Lindane $20 \mu \mathrm{M}$ & 56 & $245.2 \pm 16.7$ * & $83 \%$ & $8.2 \pm 1.3$ * & $36 \%$ & $52.2 \pm 17.2$ & $66 \%$ & $1.6 \pm 0.04$ * & $75 \%$ & $443.9 \pm 19.4$ & $85 \%$ \\
\hline control & 193 & $293.5 \pm 11.2$ & & $17.1 \pm 0.9$ & & $77.1 \pm 7.4$ & & $1.9 \pm 0.03$ & & $520.1 \pm 11$ & \\
\hline Atrazine $25 \mu \mathrm{M}$ & 172 & $262.4 \pm 10.8$ & $87 \%$ & $15.2 \pm 1$ & $96 \%$ & $78.9 \pm 8.5$ & $101 \%$ & $1.8 \pm 0.03$ & $94 \%$ & $525 \pm 9.5$ & $101 \%$ \\
\hline Atrazine $50 \mu \mathrm{M}$ & 160 & $274.1 \pm 9.8$ & $95 \%$ & $14.1 \pm 1$ * & $83 \%$ & $75.1 \pm 6.4$ & $102 \%$ & $1.7 \pm 0.03$ * & $92 \%$ & $500.4 \pm 10.1$ & $99 \%$ \\
\hline Atrazine $70 \mu \mathrm{M}$ & 112 & $277.5 \pm 11.7$ & $87 \%$ & $13.2 \pm 1.2$ * & $69 \%$ & $85.7 \pm 10.7$ & $108 \%$ & $1.8 \pm 0.03$ * & $87 \%$ & $554.5 \pm 7.2$ & $101 \%$ \\
\hline control & 387 & $294.4 \pm 6.8$ & & 20.4 & & $84.1 \pm 5.3$ & & $2.1 \pm 0.02-$ & & $535.7 \pm 5.9$ & \\
\hline BPA $5 \mu \mathrm{M}$ & 165 & $124.8 \pm 5.7 *$ & $50 \%$ & $7.6 \pm 0.8 *$ & $38 \%$ & $95.9 \pm 1.4$ & $98 \%$ & $2.3 \pm 0.03$ & $96 \%$ & $574.1 \pm 6.1$ & $101 \%$ \\
\hline BPA $10 \mu \mathrm{M}$ & 343 & $91.6 \pm 5.3$ * & $35 \%$ & $4.4 \pm 0.5 *$ & $26 \%$ & $63.7 \pm 10$ & $75 \%$ & $1.8 \pm 0.02$ * & $83 \%$ & $486.1 \pm 6.1$ & $90 \%$ \\
\hline control & 195 & $285.6 \pm 10.5$ & & 17.0 & & $78 \pm 5.3$ & & $1.7 \pm 0.03$ & & $521.9 \pm 8.3$ & \\
\hline Chlordane $10 \mu \mathrm{M}$ & 131 & $208.9 \pm 11.9 *$ & $86 \%$ & $11.7 \pm 1.1 *$ & $73 \%$ & $52.2 \pm 7.9$ & $72 \%$ & $1.6 \pm 0.03 *$ & $94 \%$ & $476.6 \pm 10.6$ & $93 \%$ \\
\hline Chlordane $25 \mu \mathrm{M}$ & 101 & $199.9 \pm 11.9$ * & $84 \%$ & $10.5 \pm 1.2$ * & $64 \%$ & $69.9 \pm 10.1$ & $95 \%$ & $1.6 \pm 0.03$ * & $96 \%$ & $490.7 \pm 10.6$ & $93 \%$ \\
\hline Chlordane $50 \mu \mathrm{M}$ & 105 & $175 \pm 11.5$ * & $65 \%$ & $6.6 \pm 1.1 *$ & $25 \%$ & $65 \pm 12.3$ & $85 \%$ & $1.5 \pm 0.02$ * & $92 \%$ & $450.6 \pm 13.1$ & $86 \%$ \\
\hline control & 281 & $336 \pm 6.2$ & & $21.2 \pm 0.6-$ & & $91.1 \pm 3.1-$ & & $2.4 \pm 0.03$ & & $562.3 \pm 4$ & \\
\hline Chlorpyrifos $10 \mu \mathrm{M}$ & 274 & $285.6 \pm 6.3$ * & $85 \%$ & $18.1 \pm 0.7$ & $76 \%$ & $77.9 \pm 8$ & $85 \%$ & $2.2 \pm 0.04$ * & $89 \%$ & $523.8 \pm 7.2$ & $90 \%$ \\
\hline Chlorpyrifos $25 \mu \mathrm{M}$ & 152 & $292.3 \pm 6.6$ * & $83 \%$ & $21.7 \pm 0.9$ & $84 \%$ & $85.9 \pm 8.3$ & $90 \%$ & $2.4 \pm 0.04$ & $94 \%$ & $544.8 \pm 8.5$ & $91 \%$ \\
\hline Chlorpyrifos $50 \mu \mathrm{M}$ & 216 & $245.1 \pm 7.2$ * & $70 \%$ & $13.8 \pm 0.8 *$ & $52 \%$ & $69 \pm 13 . .3$ & $80 \%$ & $2.1 \pm 0.03 *$ & $76 \%$ & $464 \pm 8.5$ * & $66 \%$ \\
\hline control & 193 & $379.5 \pm 9.5$ & & $24.9 \pm 0.7-$ & & $92.8 \pm 4.5$ & & $2.6 \pm 0.03$ & & $461.1 \pm 22.5$ & \\
\hline E2B $5 \mu \mathrm{M}$ & 159 & $427.6 \pm 4.4$ & $96 \%$ & $20.7 \pm 0.7$ & $85 \%$ & $98.5 \pm 1.5$ & $101 \%$ & $2.3 \pm 0.01$ & $95 \%$ & $416.1 \pm 22.1$ & $94 \%$ \\
\hline E2B $10 \mu \mathrm{M}$ & 165 & $353.8 \pm 8.6$ & $95 \%$ & $20.8 \pm 0.9$ & $94 \%$ & $93.7 \pm 5.6$ & $101 \%$ & $2.4 \pm 0.03$ & $96 \%$ & $482.6 \pm 22.8$ & $104 \%$ \\
\hline
\end{tabular}


Figure 3. The percentage of normal (light grey), malformed (dark grey) and undeveloped (black) embryos in the lindane (Lind) $20 \mu \mathrm{M}$, atrazine (Atr) $70 \mu \mathrm{M}$, bisphenol A (BPA) $10 \mu \mathrm{M}$, chlordane (Chl) $50 \mu \mathrm{M}$, chlorpyrifos (CP) $50 \mu \mathrm{M}$, estradiol benzoate (E2B) $10 \mu \mathrm{M}$. Data are presented as means \pm SEM.

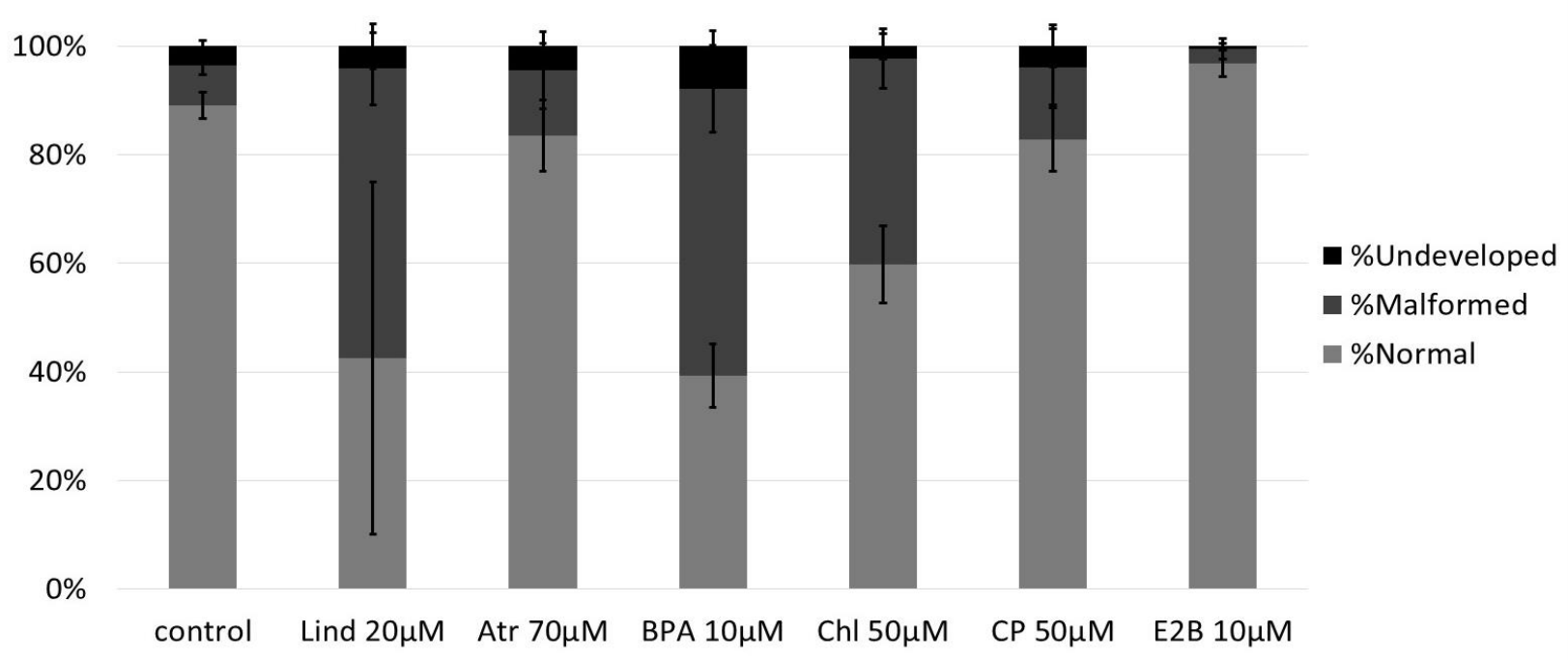


Table 5. Morphometric analysis of phenotypes observed in Phallusia mammillata larvae exposed to agonists/antagonists of nuclear receptors (NR). $\mathrm{N}$ shows the number of embryos analyzed. The table summarize the following endpoints: ocellus $(\mathrm{Oc})+$ otolith $(\mathrm{Ot})$ area $(\mu \mathrm{m} 2)$; Oc/Ot distance $(\mu \mathrm{m})$; percentage of embryos with palps (\%); trunk L/W (length/width) ratio; tail length $(\mu \mathrm{m})$. All measurements are performed at $22 \mathrm{hpf}$. Data presented as means $\pm \mathrm{S}$.E and as $\%$ to the control. Asterisks indicate significant difference compared to the control (Kruskal-Wallis test, $\mathrm{P}<0.05$ ). ATRA indicate all trans retinoic acid ; 4-OHT - 4-Hydroxytamoxifen ; DES - diethylstilbestrol ; BADGE - Bisphenol A diglycidyl ether. 
Treatment $\mathrm{N} \quad$ Oc/Ot area, Oc/Ot area Oc/Ot Oc/Ot $\%$ palps, Palps \% Trunk L/W Trunk L/W Tail length, Tail length $\mu \mathrm{m}^{2}$, mean $\pm \%$ to the distance, $\mu \mathrm{m}$, distance $\%$ means \pm S.E. to the ratio, means $\%$ to the $\mu \mathrm{m}$, means $\pm \%$ to the S.E. control mean \pm S.E. to the control \pm S.E. control S.E. control

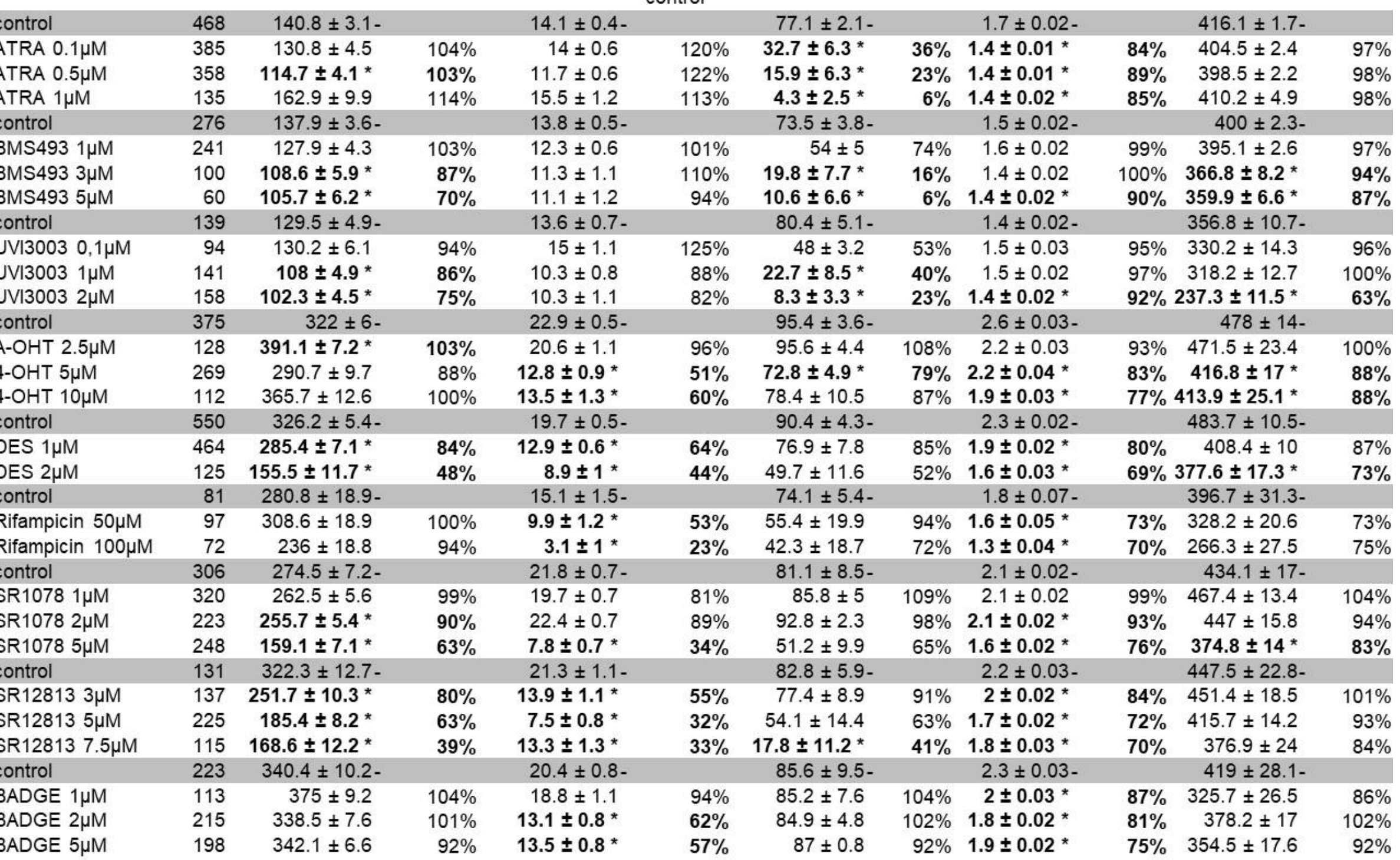


Table 6. Genotoxicity of toxicants and EDCs in developing embryos of Phallusia mammillata (7 - 9 hpf). The number of embryos with DNA aberrations was estimated from images of embryos either at gastrula or early neurula stage, where DNA was stained with Hoechst (Supplementary Fig. 4). The percentage of embryos with DNA aberrations in each culture is shown in the last column.

\begin{tabular}{|c|c|c|}
\hline $\begin{array}{l}\text { Tested } \\
\text { compound }\end{array}$ & $\begin{array}{l}\text { Number of embryos with DNA } \\
\text { aberrations / total number of } \\
\text { embryos imaged }\end{array}$ & $\begin{array}{l}\text { The percentage of } \\
\text { embryos with DNA } \\
\text { aberrations (\%) }\end{array}$ \\
\hline $0.01 \%$ DMSO & $0 / 50$ & 0 \\
\hline $\begin{array}{l}\text { Sodium azide } \\
2.5 \mathrm{mM}\end{array}$ & $21 / 30$ & 70 \\
\hline $\begin{array}{l}\text { Mitomycin } \\
60 \mu M\end{array}$ & $32 / 32$ & 100 \\
\hline $\begin{array}{l}\text { Etoposide } \\
\text { 100nM }\end{array}$ & $40 / 59$ & 68 \\
\hline $\begin{array}{l}\text { Etoposide } \\
10 \mu \mathrm{M}\end{array}$ & $30 / 30$ & 100 \\
\hline TBT $^{1}$ 50nM & $18 / 25$ & 72 \\
\hline Lindane $20 \mu \mathrm{M}$ & $10 / 20$ & 50 \\
\hline Atrazine $70 \mu M$ & $0 / 17$ & 0 \\
\hline $\begin{array}{l}\text { Chlordane } \\
50 \mu \mathrm{M}\end{array}$ & $5 / 15$ & 33 \\
\hline $\begin{array}{l}\text { Cholrpyrifos } \\
\text { 50 } \mu \mathrm{M}\end{array}$ & $5 / 18$ & 27 \\
\hline $\mathrm{BPA}^{2} 10 \mu \mathrm{M}$ & $14 / 119$ & 11 \\
\hline
\end{tabular}


Table 7. Correlation coefficients between \% embryos with DNA aberrations, normal, malformed and undeveloped. The t-test is used to establish significance of the correlation between pairs of parameters. Asterisks indicate $\mathrm{p}<0.05$ according to the Spearman's test.

\begin{tabular}{|c|c|c|c|c|}
\hline & & & & \\
& DNA aberrations (\%) & Normal (\%) & Malformed (\%) & Undeveloped (\%) \\
\hline DNA aberrations (\%) & 1.00 & $-0.93^{*}$ & 0.50 & 0.35 \\
\hline Normal (\%) & $-0.93^{*}$ & 1.00 & -0.48 & -0.48 \\
\hline Malformed (\%) & 0.50 & -0.48 & 1.00 & -0.12 \\
\hline Undeveloped (\%) & 0.35 & -0.48 & -0.12 & 1.00 \\
\hline
\end{tabular}




\section{Declaration of interests}

$\bigotimes$ The authors declare that they have no known competing financial interests or personal relationships that could have appeared to influence the work reported in this paper.

$\square$ The authors declare the following financial interests/personal relationships which may be considered as potential competing interests:

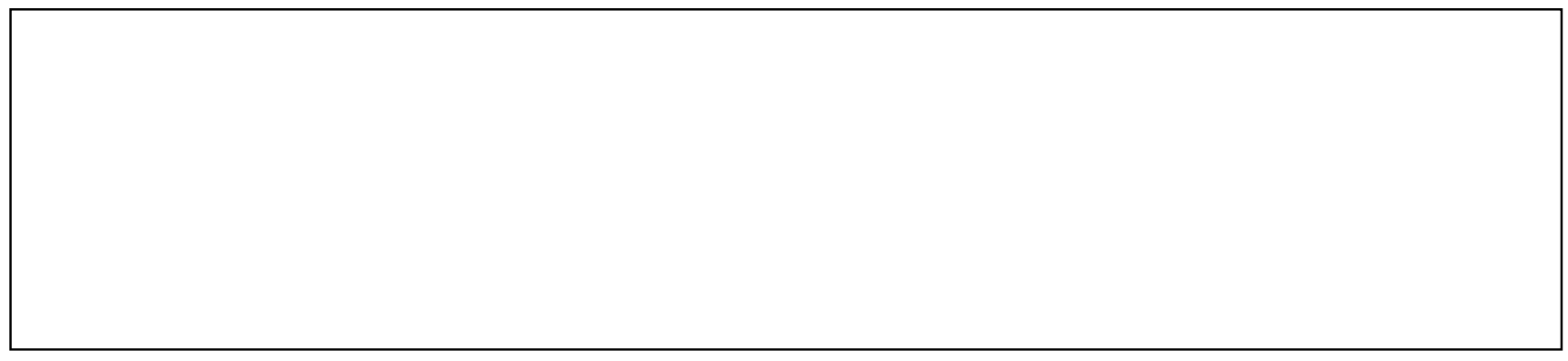


Authors contributions:

levgeniia Gazo: performed experiments; participated in data analysis; prepared a draft manuscript. Isa D. L. Gomes: performed cultures with BPA; participated in draft preparation. Thierry Savy: developed Toxicosis software. Nadine Peyrieras: participated in conceptualization of Toxicosis software. Lydia Besnardeau: assisted with experiments. Celine Hebras: assisted with experiments. Sameh Benaicha: data analysis. Manon Brunet: performed cultures with ATRA, BMS, UVI. Olena Shaliutina: performed cultures with mitomycin. Alex McDougall: coordinated the study. Rémi Dumollard: coordinated the study, participated in data analysis, edited and rewrote draft 
Click here to access/download Supplementary Material Supplementary Figures 191120.docx 